\title{
Brassica napus L. cultivars show a broad variability in their morphology, physiology and metabolite levels in response to sulfur limitations and to pathogen attack
}

\author{
Annekathrin Weese ${ }^{1}$, Philip Pallmann ${ }^{2}$, Jutta Papenbrock ${ }^{1}$ and Anja Riemenschneider ${ }^{\text {* }}$ \\ ${ }^{1}$ Institute of Botany, Leibniz University Hannover, Hannover, Germany \\ 2 Institute of Biostatistics, Leibniz University Hannover, Hannover, Germany
}

\section{Edited by:}

Agnieszka Sirko, Polish Academy of Sciences, Poland

Reviewed by:

Stanislav Kopriva, University of Cologne, Germany

Silvia Haneklaus, Julius Kühn

Institute, Germany

${ }^{*}$ Correspondence:

Anja Riemenschneider, Institute of

Botany, Leibniz University Hannover,

Herrenhäuserstr. 2, Hannover

D-30419, Germany

e-mail: riemenschneider@

botanik.uni-hannover.de
Under adequate sulfur supply, plants accumulate sulfate in the vacuoles and use sulfur-containing metabolites as storage compounds. Under sulfur-limiting conditions, these pools of stored sulfur-compounds are depleted in order to balance the nitrogen to sulfur ratio for protein synthesis. Stress conditions like sulfur limitation and/or pathogen attack induce changes in the sulfate pool and the levels of sulfur-containing metabolites, which often depend on the ecotypes or cultivars. We are interested in investigating the influence of the genetic background of canola (Brassica napus) cultivars in sulfur-limiting conditions on the resistance against Verticillium longisporum. Therefore, four commercially available $B$. napus cultivars were analyzed. These high-performing cultivars differ in some characteristics described in their cultivar pass, such as several agronomic traits, differences in the size of the root system, and resistance to certain pathogens, such as Phoma and Verticillium. The objectives of the study were to examine and explore the patterns of morphological, physiological and metabolic diversity in these B. napus cultivars at different sulfur concentrations and in the context of plant defense. Results indicate that the root systems are influenced differently by sulfur deficiency in the cultivars. Total root dry mass and length of root hairs differ not only among the cultivars but also vary in their reaction to sulfur limitation and pathogen attack. As a sensitive indicator of stress, several parameters of photosynthetic activity determined by PAM imaging showed a broad variability among the treatments. These results were supported by thermographic analysis. Levels of sulfur-containing metabolites also showed large variations. The data were interrelated to predict the specific behavior during sulfur limitation and/or pathogen attack. Advice for farming are discussed.

Keywords: canola, diurnal rhythm, elemental sulfur, metabolites, Verticillium longisporum

\section{INTRODUCTION}

Oilseed rape or canola (Brassica napus L.) belongs to the Brassicaceae family. Oilseed rape is used for the production of green fuel, human consumption, as animal feed, in the chemical and pharmaceutical industry (Friedt and Snowdon, 2009), and has an enormous economical importance for many farmers in Europe (European Commission Eurostat, 2014). ${ }^{1}$ Compared with crops such as wheat, soybean and rice, which have a long history of evolution and domestication, rapeseed is a recently domesticated species. It possibly arose as a result of interspecific hybridizations and genome doubling between diploid genotypes of turnip rape (Brassica rapa, $2 n=2 \times 10=20$, genome AA) and cabbage (Brassica oleracea, $2 n=2 \times 9=18$, genome CC) that occurred spontaneously during medieval times or earlier (Iñiguez-Luy and Federico, 2011). Vollmann and Rajcan (2009)

\footnotetext{
${ }^{1}$ European Commission Eurostat (2014). Available online at: epp.eurostat. ec.europa.eu/tgm/table.do?tab $=$ table\&init $=1$ \&language $=$ de\&pcode $=$ tag00099 \&plugin $=1$. accessed 15.09.2014
}

summarized that in general, the breeding of oil crops is a more complex undertaking than breeding of cereals or legumes because most of the oil crops are dual- or multi-purpose crops. Often simultaneous manipulations are required to create different characteristics of quality.

Oilseed rape has higher requirements for nitrogen, phosphorus and sulfur than cereals and other crops. Brassica napus plants need approximately $40-50 \mathrm{~kg}$ of nitrogen (30\% more than wheat), $8 \mathrm{~kg}$ phosphorus and $10 \mathrm{~kg}$ sulfur per metric ton of grain produced. In fact, wheat needs $15-25 \mathrm{~kg}$ sulfur ha ${ }^{-1}$, whereas $B$. napus needs $30-50 \mathrm{~kg}$ sulfur ha ${ }^{-1}$ (Bloem and Haneklaus, 2002).

The high demand of sulfur supplementation in rapeseed occurred as a cause of sulfur-deficient soils and dramatic reduction in atmospheric deposition of sulfur in recent years due to enhanced emission controls (Dämmgen et al., 1998; Lewandowska and Sirko, 2008). This reduction has had significant impact on agriculture; most notably as oilseed rape has been exhibiting sulfur deficiency symptoms. (Schnug et al., 1995). 
Under sulfur limitation [for definitions of the sulfur status see Scherer (2001)], crops begin to develop sulfur deficiency symptoms such as reduced plant growth and chlorosis of the younger leaves (Grant and Kovar, 2012). Symptoms become visible in crop plants in the following order: first in oilseed rape, potato, sugar beet, beans, peas, cereals and finally in maize. The total sulfur concentration in tissues corresponding to the first appearance of deficiency symptoms is highest in oilseed rape $\left(3.5 \mathrm{mg}\right.$ sulfur $\mathrm{g}^{-1}$ dry weight, DW) and lowest in the Gramineae (1.2 $\mathrm{mg}$ sulfur $\mathrm{g}^{-1}$ DW) (Haneklaus et al., 2007). Long term sulfur deficiency can lead to reduced yield and crop quality (Ahmad and Abdin, 2000; Scherer, 2001). An increase of diseases due to enhanced emission controls led to the hypothesis that there might be a relationship between the sulfur supply, the high sulfur demand of rape (Holmes, 1980), and defense mechanisms against fungal diseases. The hypothesis of sulfur-induced resistance (SIR) (Schnug et al., 1995) and a sulfur-enhanced defense (SED) (Kruse et al., 2007) was proposed.

In recent years, lab-scale experiments have produced substantial amounts of data supporting the conjecture that sulfurcontaining compounds play a role in pathogen defense. Arabidopsis thaliana wild-type and knockout plants were used to investigate the role of cysteine in response to pathogen attack by using Pseudomonas syringae pv. tomato, Botrytis cinerea (Álvarez et al., 2011), and Alternaria brassicicola (Kruse et al., 2012). Cysteine is a precursor for essential vitamins, cofactors, and many defense compounds such as glucosinolates (GSL), thionins, or phytoalexins (Smith and Kirkegaard, 2002; Van Wees et al., 2003; Rausch and Wachter, 2005). In infected plants, the cysteine content decreased by $24-28 \%$ but a $14-15 \%$ increase in glutathione content was observed (Álvarez et al., 2011).

Williams et al. (2002) demonstrated that elemental sulfur was formed and accumulated in tomato plants in response to infection with Verticillium dahliae. In older leaves, the sulfate content increased after 14 days post-infection (dpi), indicating that sulfate levels in infected plants were dependent on the leaf age. Significant changes in cysteine levels of plants infected with $V$. dahliae were measured in the stem vascular tissue. The same was observed for the glutathione content in leaves. In the past, reduction of sulfur containing metabolites especially in young leaves was shown in B. napus under sulfur limitation (Blake-Kalff et al., 1998).

Field experiments with B. napus and Pyrenopeziza brassicae have shown an increase of the thiol concentration. Crops were able to react to a fungal infection and had a greater potential to release $\mathrm{H}_{2} \mathrm{~S}$, which is reflected by a positive correlation between L-cysteine desulfhydrase enzyme activity and fungal infection levels (Bloem et al., 2004). Consecutive greenhouse experiments have shown that already after one dpi, the $\mathrm{H}_{2} \mathrm{~S}$ emission of plants grown under full sulfur supply increased strongly (Bloem et al., 2012).

Haneklaus et al. (2007) concluded that under sulfur deficiency, $B$. napus develops the most distinctive and most specific expression of phenotypic symptoms. No difference in the symptomatology of sulfur deficiency was observed in high and low containing GSL cultivars. Differences in their susceptibility against fungal infections were not unambiguously demonstrated so far.
Several winter rape cultivars with low erucic acid and low total GSL contents, $<30 \mu \mathrm{mol} \mathrm{g}^{-1}$ defatted seed meal, were investigated to determine their contents of GSL in leaves and roots. Also in these organs, the GSL levels are rather low. In leaves, the concentrations of total GSL were about $3 \mu \mathrm{mol} \mathrm{g}^{-1} \mathrm{DM}$ and in roots, about $18 \mu \mathrm{mol} \mathrm{g}^{-1} \mathrm{DM}$ (Eberlein et al., 1998). In very recent high-performance cultivars, the GSL contents are even lower (see Table 1) and probably do not contribute much to the total sulfur amount in modern B. napus cultivars (Eberlein et al., 1998).

As mentioned before, yield reductions of $B$. napus is caused by not only a sulfur deficiency, but also a Verticillium infection (Dunker et al., 2008). The soil-borne vascular fungal pathogen Verticillium longisporum is one of the most important yieldminimizing pathogens of oilseed rape, and there has been no approved fungicide available until now (Heale and Karapapa, 1999; Friedt and Snowdon, 2009). In addition, the fungus survives in the soil for long periods through the production of microsclerotia. Therefore, selection of suitable resistant cultivars and optimized cultivation methods need to be developed. As was reported previously, many pathogens attack plants during dawn by dispersing their spores (Wang et al., 2011). However, there is no knowledge of exactly when $V$. longisporum attacks. Interestingly, expression studies of adenosine $5^{\prime}$-phosphosulfate reductase (APR) indicate that sulfur assimilation is controlled in a diurnal way (Kopriva et al., 1999).

Results from Burandt et al. (2001) indicate that the capability to use available soil sulfur is genetically controlled. Therefore, different high-performance cultivars currently cultivated in Europe were analyzed. The high-performance cultivar plants were compared at early stages of development under controlled conditions, irrespective of the final yield. (I) We were interested in the metabolic reaction to sulfur limitation and the reaction of B. napus cultivars to pathogen attack of $V$. longisporum. (II) To better understand the mechanisms of SED of the high-sulfurdemanding $B$. napus plants, the influence of time points during the day was analyzed. (III) The plants were comprehensively analyzed by measuring biometrical and physiological parameters, levels of several sulfur- and non-sulfur containing metabolites, and gene expression levels. After analyzing B. napus plants in an early stage of development, a recommendation for a promising cultivar to avoid yield loss is given.

\section{MATERIALS AND METHODS PLANT MATERIAL AND GROWTH CONDITIONS \\ Plant material}

Winter oilseed rape seeds from the cultivars Compass, Exocet, Genie and King10 were obtained from the $D^{2}$ eutsche Saatveredelung AG (DSV) (Lippstadt, Germany) (http://www. dsv-saaten.de/raps/winterraps/sorten). The most important traits are summarized in Table 1. Compass is an MSL-hybrid (MSL, Male Sterility Lembke), has an excellent resistance to lodging of insects and has been on the market in Germany since 2009. Exocet is an OGURA-hybrid, which has been introduced to the market in 2005 (OGURA, expressed as cytoplasmatic male

\footnotetext{
${ }^{2}$ Deutsche Saatveredelung, A. G. (2014). Available online at: http://www.dsvsaaten.de/raps/winterraps/sorten [Accessed 01. 07. 2014]
} 
Table 1 | Summary of available data about the different cultivars.

\begin{tabular}{|c|c|c|c|c|c|c|}
\hline Cultivar & Type & Vigor & $\begin{array}{l}\text { Resistance to } \\
\text { Verticillium wilt }\end{array}$ & Root system & Oil content & $\begin{array}{c}\text { GSL content } \\
{\left[\mu \mathrm{mol} \mathrm{g}^{-1} \text { seed DM] }\right.}\end{array}$ \\
\hline Compass & $\mathrm{H}$ & +++ & ++++ & ++++ & ++++++ & $<18$ \\
\hline Genie & $\mathrm{H}$ & ++++++ & ++++ & +++ & +++++ & $<25$ \\
\hline King10 & L & ++++++ & ++++++ & - & ++++++ & $<25$ \\
\hline
\end{tabular}

H, hybrid; L, line-bred; +, intensity; -, no information. The intensity is rated based on parameter values found on the websites given in Materials and Methods (Range from + very low to ++++++ very high). DM, dry mass; GSL, glucosinolates.

sterility, originated from Raphanus sativus) (Ogura, 1968). It has a high grain yield potential and excellent resistance against blackleg. Genie is an MSL-hybrid and has been introduced in 2010. It is very vital and has an extremely low temperature resistance. In addition to the three hybrid varieties, we have chosen line King10 that is a line-bred cultivar and was marketauthorized in 2009. The yield of line King10 is comparable with new high-performance hybrids. The three varieties and the line will be summed up as cultivars. More information about the cultivars can be found on several websites (www. rapool.de ${ }^{3}$, www.roth-agrar.de ${ }^{4}$ and www.dsv-saaten.de/raps/ winterraps/sorten).

\section{Plant growth}

For infection experiments, 30 seeds per plate of all four cultivars were sterilized and placed on plates containing solidified Blake-Kalff medium (Blake-Kalff et al., 1998) with $1 \mathrm{mM} \mathrm{MgSO}_{4}$. After 7 day of germination in a climatic chamber $\left[22^{\circ} \mathrm{C}, 70 \%\right.$ humidity, $12 \mathrm{~h} \mathrm{light} / 12 \mathrm{~h}$ dark, $480 \mu \mathrm{mol} \mathrm{m}^{-2} \mathrm{~s}^{-1}$ (lamp type CMT 360LS/W/BH-E40, Eye Lighting Europe Ltd, Uxbridge, UK)], 45 seedlings were mock-inoculated with water or root dip-inoculated for $30 \mathrm{~min}$ (the production of spores is described below) and transferred in pots ( $8 \mathrm{~cm}$ diameter) filled with sand (0-2 mm grain size, Hornbach, Hannover, Germany). After preexperiments reclined to experiments of Blake-Kalff et al. (1998), three different sulfur regimes with respect to sulfur concentration and volume of nutrient solution per week were chosen. As a control, one third of the pots were irrigated with Blake-Kalff medium containing $1 \mathrm{mM} \mathrm{MgSO} 4$ (full sulfur supply, optimal growth conditions), the other pots were treated with Blake-Kalff medium containing $0.025 \mathrm{mM}$ (moderate sulfur limitation) or $0.010 \mathrm{mM}$ $\mathrm{MgSO}_{4}$ (severe sulfur limitation) and additional $\mathrm{MgCl}_{2}$. Each pot was watered with $150 \mathrm{ml}$ of a nutrient solution weekly. After 14 $\mathrm{dpi}$, the leaves and the stems of three plants of each treatment were harvested every $4 \mathrm{~h}$, beginning $1 \mathrm{~h}$ before light was switched on (labeled $0,4,8,12$, and $16 \mathrm{~h}$ in the graphs). Plant material was pooled and directly frozen in liquid nitrogen for further analyses.

\section{Pathogen cultivation}

For the production of Verticillium longisporum spores, $500 \mu \mathrm{l}$ of a frozen spore culture (isolate VL43, Enyck et al., 2009) was

\footnotetext{
${ }^{3}$ Rapool (2014). Available online at: www.rapool.de [Accessed 01. 07. 2014]

${ }^{4}$ Roth-Agrar (2014). Available online at: roth-agrar.de/produkte/saatgut/ saatraps/sortenliste/sortenliste_saatraps_herbst_2013 [Accessed 01. 07. 2014]
}

cultivated in $500 \mathrm{ml}$ potato dextrose liquid medium (Difco PDB, Becton, Dickinson and Company, New Jersey, USA) in $1 \mathrm{~L}$ flasks. The flasks were incubated at $23^{\circ} \mathrm{C}$ in a rotary incubator at $150 \mathrm{rpm}$ in darkness for 2 weeks until a dense spore suspension was produced. The concentration of the filtered spores per $\mathrm{ml}$ suspension was determined using a Thoma chamber and diluted with sterile water ( $\mathrm{pH} 7.0)$ to $1^{*} 10^{6}$ spores per ml.

\section{THERMOGRAPHIC ANALYSIS}

The evaporative cooling as water is lost through stomata is an important component of the local leaf energy balance. Thus, leaf temperature can provide a sensitive indicator of leaf conductance to water vapor (Jones, 2007). In several studies, leaf temperature was used as an indicator of water stress, salt stress and nutrition deficiency induced stress (Chaerle et al., 2007; James and Sirault, 2012; Guretzki and Papenbrock, 2013). Furthermore, an influence due to pests and disease on the leaf temperature was observed (Allègre et al., 2007). Therefore, in this study, thermographic analysis was carried out to analyze early symptoms of stress caused by sulfur limitation or pathogen attack. The thermal imaging investigation was carried out with the camera T360 (FLIR Systems, Wilsonville, USA) according to Grant et al. (2006), in order to measure the surface temperature on plant leaves. For an optimal signal-to-noise ratio, the camera was turned on at least $30 \mathrm{~min}$ before the first thermographic picture was taken. For analyzing the pictures of three plants per cultivar and per treatment, the program ThermoCam Researcher 2.10 FLIR QuickReport 1.2 SP2 (FLIR Systems, Wilsonville, USA) was used. The parameters were set for each image to emissivity 0.95 , reflected apparent temperature $22^{\circ} \mathrm{C}$, atmospheric temperature $22^{\circ} \mathrm{C}$, relative humidity $70 \%$ and distance $0.8 \mathrm{~m}$.

\section{CHLOROPHYLL FLUORESCENCE MEASUREMENTS}

Chlorophyll fluorescence was determined by a PAMM series device and ImagingWin v2.32 software (Heinz Walz, Effeltrich, Germany). The measurements were performed with up to six areas of interest (AOI, points on the leaves where the measurement data points were taken) on different expanded leaves. Light curves using different photosynthetically active radiations (PAR) were examined as presented in the manufacturer's handbook. Because of the use of the filter plate IMAG-MAX/F, the effective PAR values were about $15 \%$ lower. Before taking the measurement, the plants were dark adapted for $20 \mathrm{~min}$. The parameters $\mathrm{F}_{\mathrm{v}} / \mathrm{F}_{\mathrm{m}}$ (maximal PS II quantum yield) and $\mathrm{Y}$ (II) (effective PS II quantum yield) were analyzed (for background information: 
Baker, 2008; Sperdouli and Moustakas, 2012). $\mathrm{F}_{\mathrm{v}} / \mathrm{F}_{\mathrm{m}}$ values were obtained from the false-color images, created by ImagingWin software. Measurements $(n=5-8)$ were performed $1 \mathrm{~h}$ after light was switched on.

\section{BIOMASS MEASUREMENTS}

For the analysis of the biomass, all plants of the cultivars were harvested, and material was divided into shoot, stem, and root categories, before being weighed. When weighing the roots, all soil particles were removed by washing the whole root system of one plant and drying it carefully with tissue. The plant material was dried in paper bags at $80^{\circ} \mathrm{C}$ for 4 day, and the dry mass (DM) was determined.

\section{MORPHOLOGY}

Ten sterilized seeds per plate were germinated for 5 day on three plates with Blake-Kalff medium, containing $1 \mathrm{mM}$ $\mathrm{MgSO}_{4} / 0.010 \mathrm{mM}$ sulfate. Additionally, on half of the plates $0.5 \mu \mathrm{l}$ of a $1^{*} 10^{6}$ spore suspension was applied. The roots of the seedlings were sectioned in an investigation zone that lay 1$2 \mathrm{~cm}$ below the root crown. Pictures of the primary roots were taken with a camera installed on a binocular (Olympus SZ2ILST, Tokyo, Japan). The root hair lengths of five plants were determined at the computer using a ruler.

\section{METABOLIC ANALYSIS}

\section{Elemental analysis of plant material}

For the analytical measurements, pooled samples were measured at least three times, up to six times. Dry plant material was ground to fine powder (MM 400, Retsch GmbH, Haan, Germany). About $38 \mathrm{mg}$ of the ground powder was incinerated for a minimum of $8 \mathrm{~h}$ in a muffle furnace (M104, Thermo Fisher Scientific Corporation, Waltham, Massachusetts, USA) for each cultivar and treatment. After cooling the samples to room temperature (RT) (between 21 and $23^{\circ} \mathrm{C}$ ), $1.5 \mathrm{ml}$ of $66 \%$ nitric acid was added. After $10 \mathrm{~min}, 13.5 \mathrm{ml}$ of ultrapure water was pipetted to the samples. The solutions were filtered $(0.45 \mu \mathrm{m}$ pore size, Carl Roth, Karlsruhe, Germany) and stored in vials at $-20^{\circ} \mathrm{C}$ before final analysis. The samples were analyzed by inductively coupled plasma optical emission spectrometry (ICPOES) (iCAP 6000 ICP Spectrometer, Thermo Fisher Scientific Corporation). Fluctuations of the results were around 5\% for sulfur and phosphorus. Iron measurement results showed fluctuations of about $20 \%$.

\section{Sulfate determination and analysis of soluble thiol compounds}

Sulfate was determined by capillary electrophoresis (CE) in the following way: $30 \mathrm{mg}$ of deep-frozen, fine-ground plant material was solved in $700 \mu \mathrm{l} \mathrm{HPLC}$ grade $\mathrm{H}_{2} \mathrm{O}$, mixed for $1 \mathrm{~min}$, incubated at RT for $10 \mathrm{~min}$, mixed again for $1 \mathrm{~min}$ and centrifuged for $10 \mathrm{~min}$ at $13,200 \times \mathrm{g}$ at $4^{\circ} \mathrm{C}$. The supernatant was transferred to a new reaction tube, frozen overnight, and after thawing, centrifuged another $10 \mathrm{~min}$. The supernatant was transferred to a $500 \mu \mathrm{l}$ reaction tube and used for $\mathrm{CE}$ analysis $\left(\mathrm{P} / \mathrm{ACE}^{\mathrm{TM}}\right.$ MDQ Capillary Electrophoresis System with MDQ-PDA detector, Beckman Coulter, Krefeld, Germany). Separations were performed in a Beckman Coulter eCAP ${ }^{\mathrm{TM}} \mathrm{CE}-\mathrm{MS}$ capillary (fused silica, $75 \mu \mathrm{m}$ i.d., $57 \mathrm{~cm}$ total length, $50 \mathrm{~cm}$ effective length).
Before starting the analyses, the capillary was rinsed with HPLC grade $\mathrm{H}_{2} \mathrm{O}$ for $10 \mathrm{~min}$ and equilibrated with the background electrolyte Basic Anion Buffer for HPCE (Agilent Technologies, Waldbronn, Germany) at 14.5 psi for $10 \mathrm{~min}$. Injection was done by applying 0.7 psi for $6 \mathrm{~s}$. Separation of the samples was performed by applying $14 \mathrm{kV}, 22^{\circ} \mathrm{C}$, reverse polarity for $10 \mathrm{~min}$. Samples were detected at $350 \mathrm{~nm}$ with a bandwidth of $20 \mathrm{~nm}$. Calibration graphs for sulfate were generated with 78-10,000 $\mu \mathrm{M}$ $\mathrm{Na}_{2} \mathrm{SO}_{4}$. The detection limit for this method is about $10^{-13}$ $10^{-16}$ mol. Evaluation of the electropherograms was done with Karat 327.0 software. The determination of thiols was done according to Riemenschneider et al. (2005).

\section{Determination of phenols and flavonoids}

To $50 \mathrm{mg}$ of ground leaf material $800 \mu \mathrm{l}$ of $80 \%$ methanol was added, mixed for $10 \mathrm{~min}$ and centrifuged for $5 \mathrm{~min}$. The pellet was re-extracted three times with $400 \mu \mathrm{l}$ methanol and the supernatants were combined. The whole sample was centrifuged and the supernatant stored at $-70^{\circ} \mathrm{C}$.

Based on the method of Dudonné et al. (2009), $100 \mu \mathrm{L}$ of water was pipetted into a 96-well microtiter plate. Triplicates of $10 \mu \mathrm{L}$ sample, blank (80\% methanol) or gallic acid standard (5-250 $\mu \mathrm{g} \mathrm{mL}^{-1}$ ) and finally $10 \mu \mathrm{L}$ Folin Ciocalteu reagent were added. After incubation for $8 \mathrm{~min}$ and addition of $100 \mu \mathrm{L} 7 \%$ sodium carbonate, the plate was incubated for $100 \mathrm{~min}$ and measured at $765 \mathrm{~nm}$. Total phenols were calculated from a standard curve.

Flavonoids were analyzed based on Dewanto et al. (2002). To each well of a clear 96-well microtiter plate $150 \mu \mathrm{l}$ water, $25 \mu \mathrm{l}$ sample or catechin hydrate standard $\left(10-400 \mu \mathrm{g} \mathrm{ml}^{-1}\right)$ or $80 \%$ methanol as blank (in triplicate) and $10 \mu \mathrm{l} 3.75 \% \mathrm{NaNO}_{3}$ were added. After $6 \mathrm{~min}$ incubation, $15 \mu \mathrm{L} 10 \% \mathrm{AlCl}_{3}$ were added. After $5 \mathrm{~min}$ incubation, $50 \mu \mathrm{l} 1 \mathrm{M} \mathrm{NaOH}$ was added and the total flavonoids were calculated from a standard curve based on the absorption at $510 \mathrm{~nm}$.

\section{Measurements of anthocyanins}

For the determination of the anthocyanin content, $1 \mathrm{ml} 1 \% \mathrm{HCl}$ in methanol and $0.5 \mathrm{ml} \mathrm{H}_{2} \mathrm{O}$ were added to $50 \mathrm{mg}$ of ground plant material and incubated overnight at $4^{\circ} \mathrm{C}$. Then the samples were centrifuged for $15 \mathrm{~min}$ at $21,000 \times \mathrm{g}$ at RT. The supernatants were measured at 530 and $675 \mathrm{~nm}$ for the anthocyanin concentration and degraded products of the chlorophyll determination, respectively (Rabino and Mancinelli, 1986). The formula for the calculation was: $c_{\text {anthocyanin }}=\mathrm{AU}\left(\mathrm{A}_{530}-\left(0.25^{*} \mathrm{~A}_{657}\right)\right) / \mathrm{g}$ FM.

\section{SEOUENCE ANALYSIS}

For the primer design, sequences homologous of A. thaliana DNA sequences for APR2 and APR3 sequences were searched in the B. napus database (Computational Biology and Functional Genomics Laboratory, 2014) using BLAST. The data bank uses parts of short homologous sequences (high-fidelity virtual transcripts; TC-sequences, tentative consensus sequences) to generate EST sequences (Quackenbush et al., 2000) that were used for the primer pair design (Primer Design version 2.2, Scientific \& Educational Software, Cary, USA). For the design of the primer pairs for the amplification of cDNA fragments of sulfate transporter, the respective homologous sequences from 
Brassica oleracea were used (Buchner et al., 2004a), because the $B$. napus sequences were still not available. The primers were used to amplify cDNA fragments between 339 and $973 \mathrm{bp}$ (Table 2).

\section{NORTHERN BLOTTING}

Total RNA was extracted according to Sokolowsky et al. (1990) from ground plant material and quantified spectrophotometrically. Fifteen $\mu \mathrm{g}$ of the RNA were separated on 1\% denaturing agarose-formaldehyde gels. Equal loading was controlled by staining the gels with ethidium bromide. After RNA transfer onto nylon membranes, they were probed with digoxigenin-labeled cDNA probes obtained by PCR (PCR DIG probe synthesis kit, Roche, Mannheim, Germany). To amplify the respective probes, the sequence-specific primers listed in Table 2 were used. The colorimetric detection method with nitroblue tetrazolium (NBT) and 5-bromo-4-chloro-3-indolyl-phosphate (BCIP) as substrates for alkaline phosphatase was applied. Quantitative analysis of the Northern blot results was done by GelAnalyzer ${ }^{5}$ (http://www. gelanalyzer.com). None of the common housekeeping genes was expressed under sulfur deficiency, pathogen attack, and diurnal rhythm in a constitutive way. Therefore, calculations were done in the following way: For each membrane, the band intensity of the first sample $(0 \mathrm{~h})$ was set to $100 \%$. The intensities of the following bands were referred to the intensity of the first band.

\section{STATISTICAL ANALYSIS}

The biomass data were evaluated using a Three-Way ANOVA with DM as dependent variable (log-transformed to meet linear model assumptions such as normality and homogeneity of variances) and cultivar, infection, and S concentration as independent factors. Significance of factors and their interactions was assessed by means of F-tests; all interaction terms except cultivar: infection proved non-significant and were thus eliminated from the model. To pinpoint significant differences among factor levels, we applied Tukey tests (i.e., pairwise mean comparisons) controlling the rate of type I errors at 5\%. In the presence of interactions, the Tukey comparisons were carried out separately for each level of the interacting factor.

${ }^{5}$ Gelanalyzer (2014). Available online at: GelAnalyzer.com [Accessed 16. 09. 2014]
A similar ANOVA model was fit to the (logarithmized) shoot-to-root ratios; here all interaction terms turned out to be non-significant, so we simplified the model to main effects only before performing Tukey comparisons.

Leaf temperatures and quantum yields were analyzed with ANOVA-type linear mixed-effects models including leaf-specific random effects to account for correlation among 10 replicated measurements from each of five leaves. These models could not be simplified due to all two- and three-way interactions of the factors cultivar, infection, and S concentration being significant and hence not omissible. In consequence, pairwise Tukey comparisons were carried out separately for each combination of factor levels.

All statistical computations were done in R 3.1.1 (R Core Team, 2014). The graphs were generated with SigmaPlot 12.5 (Systat Software, Inc., San Jose, CA).

\section{RESULTS}

\section{MORPHOLOGY}

For the determination of the root morphology, sterilized oilseed rape seeds were grown for 5 day on Blake-Kalff medium with and without an adjusted spore suspension. The roots were separated in sections and the pictures were taken in the section one to two $\mathrm{cm}$ below the crown (Figure 1A). As visible on the pictures, Genie (D) has significantly shorter root hairs when comparing them with the cultivars Compass (B) and Exocet (C). The root hairs of Genie have an average length of $0.58 \pm 0.08 \mathrm{~mm}$. Figure 1 shows that the length of the hairs is different between King10 (E) and either of Exocet and Genie. As demonstrated by the statistical analyses (Table S1), there are no significant differences between the cultivars Compass and Exocet, with an average root hair length of 1.16 and $1.14 \mathrm{~mm}$. No differences in the root length could be observed at seedlings grown with less sulfate or when incubated with $V$. longisporum spores in comparison to control conditions.

\section{BIOMASS PRODUCTION}

Because of the remarkable differences in the root hair length, the biomass of the organs and especially the root system was analyzed in more detail. Oilseed rape plants were cultivated as described, weighed and dried. No visible symptoms due to infection were observed. The total DM and the shoot to root ratio was calculated (Figure 2). The total DM of all non-infected (C) and infected

Table 2 | Primers used in this study.

\begin{tabular}{|c|c|c|c|c|}
\hline Primer pairs & B. napus DFCI TC No. & A. thaliana accession No. & Sequences from $5^{\prime}$ to $3^{\prime}$ & bp \\
\hline P227BoST4;2as & & & GTGTACGCTTCTGGATACTGC & \\
\hline P744_BnAPR2_rev & & & GCGAATCGACATCTCTATGCTC & \\
\hline P745_BnAPR3_for & TC186950 & At4g21990 & CATCAAGGAGAACAGCAACGCA & 339 \\
\hline
\end{tabular}

Known sequences from $A$. thaliana genes were used to find homologous gene sequences from B. napus or B. oleracea. Blasted sequences (compbio.dfci.harvard.edu) were used to create the primer pairs (Primer Design version 2.2). The annealing temperature was $55.3^{\circ} \mathrm{C}$ for all primer pairs. $S$, sense; as, antisense; for, forward; rev, reverse; DFCl, Dana-Faber Cancer Institute; TC, tentative consensus. 

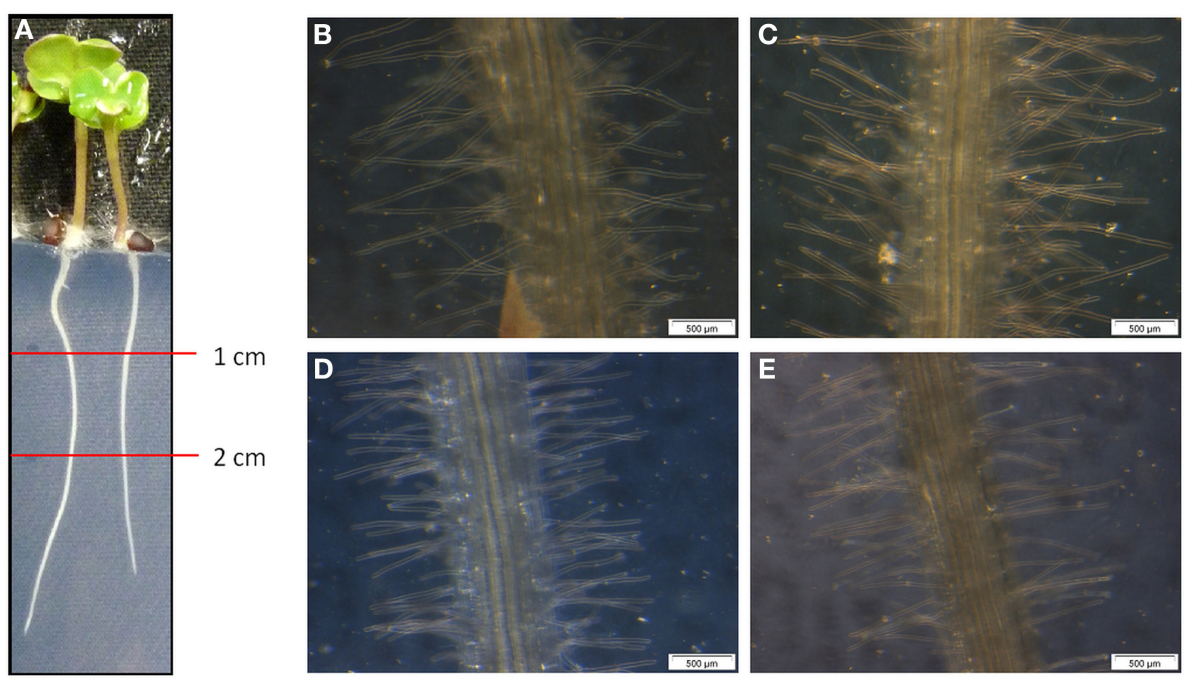

FIGURE 1 | Microscopy of root hairs. At 5-day-old seedlings of winter oilseed rape the length of the root hairs was measured using a ruler and a binocular starting one cm below the root crown. (A) 5-day-old seedling, (B) Compass, (C) Exocet, (D) Genie, and (E) King10.

(INF) cultivars is significantly decreased under sulfur deficiency, whereas no significant differences were observed between the deficiency conditions. Plants of the cultivar Exocet developed the highest leaf biomass with an average DM of up to $0.540 \pm$ $0.147 \mathrm{~g}$ as mean values. Under sulfur limitation the biomass of leaves $(-31.3 \%)$ and stems $(-27.3 \%)$ decreased significantly in non-infected plants (data not shown).

Depending on the cultivar, the treatment with the fungus led to different DM. Highly significant reductions of DM in comparison to control were measured for Exocet and Genie. In infected plants, Exocet is the only cultivar showing significantly decreased biomass in all three organs (data not shown). Control plants of King10 developed significantly less DM compared to Exocet and Compass, Genie developed significantly less DM than Compass. Upon infection a significantly higher DM was determined for Compass in comparison to all other cultivars (Table S2).

As expected, the shoot to root ratio is significantly higher in plants grown under full sulfur supply compared to sulfur deficiency conditions, whereas the fungal infection has no effect. To distinguish Compass plants achieved the significantly lowest shoot to root ratio (Figure 2B, Table S3).

\section{PHYSIOLOGICAL MEASUREMENTS}

To detect small effects of sulfur limitation and especially of pathogen attack on the cultivars at an early stage, physiological measurements were conducted. The non-invasive method of analyzing the leaf temperature with a thermo camera was used (Figure 3).

In non-infected plants, the fertilization of the different cultivars generated no significant differences in the leaf temperature. Only for plants grown under sulfur deficiency did the infection led to increasing leaf temperature. Statistical analyses revealed significantly substantial increased leaf temperature as compared with 1 and $0.01 \mathrm{mM} \mathrm{MgSO}_{4}$ in the cultivars Compass and
King10 grown with $0.025 \mathrm{mM} \mathrm{MgSO} 4$ after $14 \mathrm{dpi}$. The temperature increased significantly in Compass and King10 $(0.025 \mathrm{mM}$ $\left.\mathrm{MgSO}_{4}\right)$, whereas the temperature decreased under $0.01 \mathrm{mM}$ $\mathrm{MgSO}_{4}$ in Compass in comparison to the other cultivars. Thus, differences were measured with low sulfur supply $(0.01 \mathrm{mM})$ and infection, in which King10 showed the highest and Compass the lowest temperature. Results obtained from infected plants with the thermo camera clearly indicate that significant differences between the different cultivars only occur under sulfur limitation (Table S4).

Chlorophyll fluorescence measurements were done with noninfected and infected plants grown with different sulfur concentrations (Figure 4). Independently of the sulfur supply, the $\mathrm{F}_{\mathrm{v}} / \mathrm{F}_{\mathrm{m}}$ values range between 0.714 and 0.831 (data not shown), indicating photosynthetic activity in the same range when grown at higher or lower sulfur concentrations (Kitajima and Butler, 1975). Under full sulfur supply, Compass and King10 performed better (around 5\%) than Exocet and Genie. A slight decrease of the quantum yield was observed in Compass and Exocet under sulfur limitation. The sulfur limitation decreased the quantum yield of photosystem II in King10 strongly. The quantum yield of Genie plants remains almost constant.

No significant differences were obtained for plants grown under full sulfur supply after infection. Infection with the fungus $V$. longisporum led to a significant decrease of the quantum yield of plants grown under sulfur limiting conditions from approximately $4.5-41 \%$. The performance of King 10 was not significantly influenced by infection (Table S5).

\section{METABOLIC ANALYSIS}

\section{Elements}

Plant material of three plants per time point were dried and used for the elemental analysis (Figure 5). The control plants fed with $1 \mathrm{mM}$ sulfate showed amounts in a range between 4 and $7 \mathrm{mg}$ sulfur per g DM (Figure 5). Under sulfur limitation in all cultivars, 

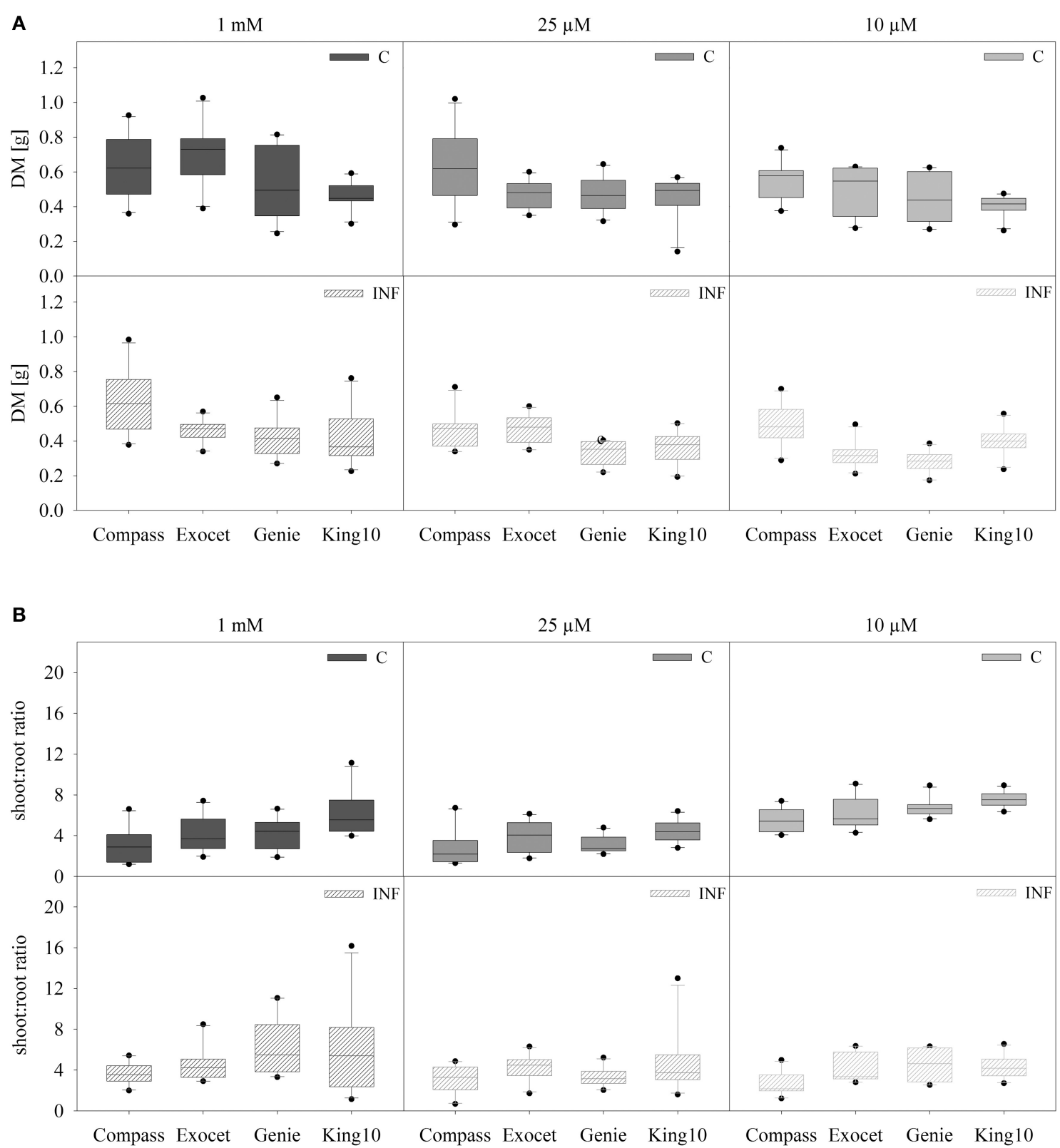

FIGURE 2 | Biomass analysis. Seven-day-old seedlings of the cultivars were either mock-inoculated (C) or infected with $V$. longisporum spores (INF).

Plants were grown under full sulfur supply ( $1 \mathrm{mM} \mathrm{MgSO}_{4}$ ) and under sulfur limitation $\left(0.025 \mathrm{mM}\right.$ and $\left.0.010 \mathrm{mM} \mathrm{MgSO}_{4}\right)$ in a climate chamber for $14 \mathrm{dpi}$.
The total dry mass (DM) (A) and the shoot to root ratio (B) of ten plants with five leaves fully expanded per treatment are presented. Data are represented as box plots. Filled boxes present non-infected plants $(\mathrm{C})$ and striped boxes the corresponding results of infected plants (INF). the sulfur content decreased below $2.18 \mathrm{mg} \mathrm{g}^{-1} \mathrm{DM}$. Calculated over the time range of the day Genie incorporated the highest amounts of sulfur in control plants followed by Compass. On average, Exocet accumulated 20\% less sulfur than Genie. King10 incorporated 3.78 times less sulfur in plants with $0.01 \mathrm{mM}$ than control plants. In control plants of Compass sulfur, values show deviations over the day with a maximum at $4 \mathrm{~h}$ with $7.20 \mathrm{mg}$ $\mathrm{g}^{-1} \mathrm{DM}$.

Infected plants of all cultivars fed with $1 \mathrm{mM} \mathrm{MgSO}_{4}$ incorporated more sulfur in the shoots than the control plants.
Interestingly, King10 incorporated over the whole time range higher sulfur amounts $\left(7.26 \mathrm{mg}\right.$ sulfur $\left.\mathrm{g}^{-1} \mathrm{DM}\right)$ in the plants grown with full sulfur supply. Under sulfur limiting conditions plants infected with the fungus incorporated more sulfur than the control plants. In Genie, the sulfur content increased by 30 , 66 , and $80 \%$ compared with the control plants fed with 1, 0.025 and $0.01 \mathrm{mM} \mathrm{MgSO}_{4}$.

Subsequently, iron and phosphorus were analyzed because both elements are, e.g., indispensable for energy transfer and structural components (Expert et al., 2012). Deficiencies of 


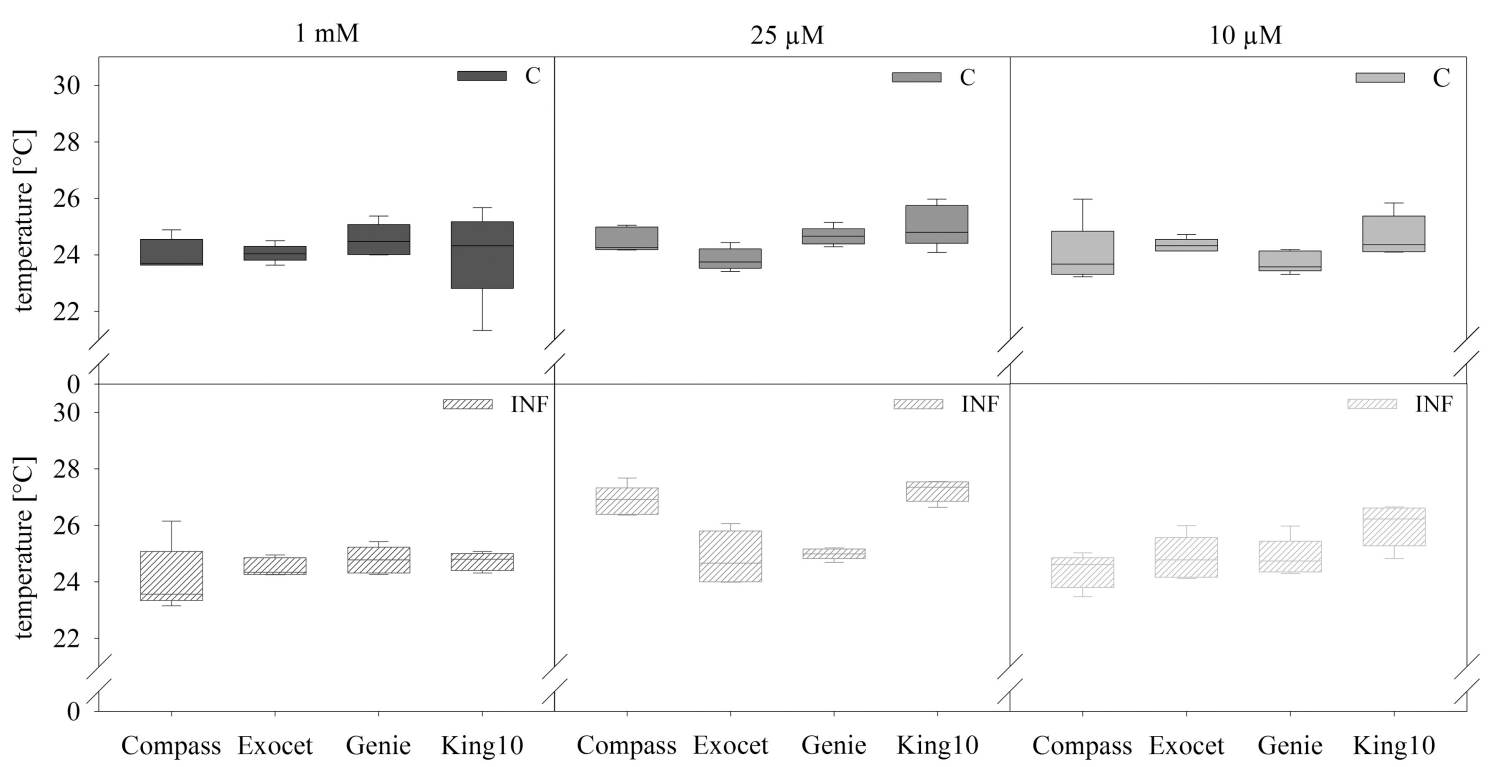

FIGURE 3 | Thermal imaging. Pictures of plants with five leaves fully expanded treated as described for Figure $\mathbf{2}$ were obtained by thermography. Results show the temperature in ${ }^{\circ} \mathrm{C}$ of leaves and represent the data as box plots of five plants per treatment with 10 dots chosen on fully expanded leaves. Filled boxes present non-infected plants $(\mathrm{C})$ and striped boxes the corresponding results of infected plants (INF).

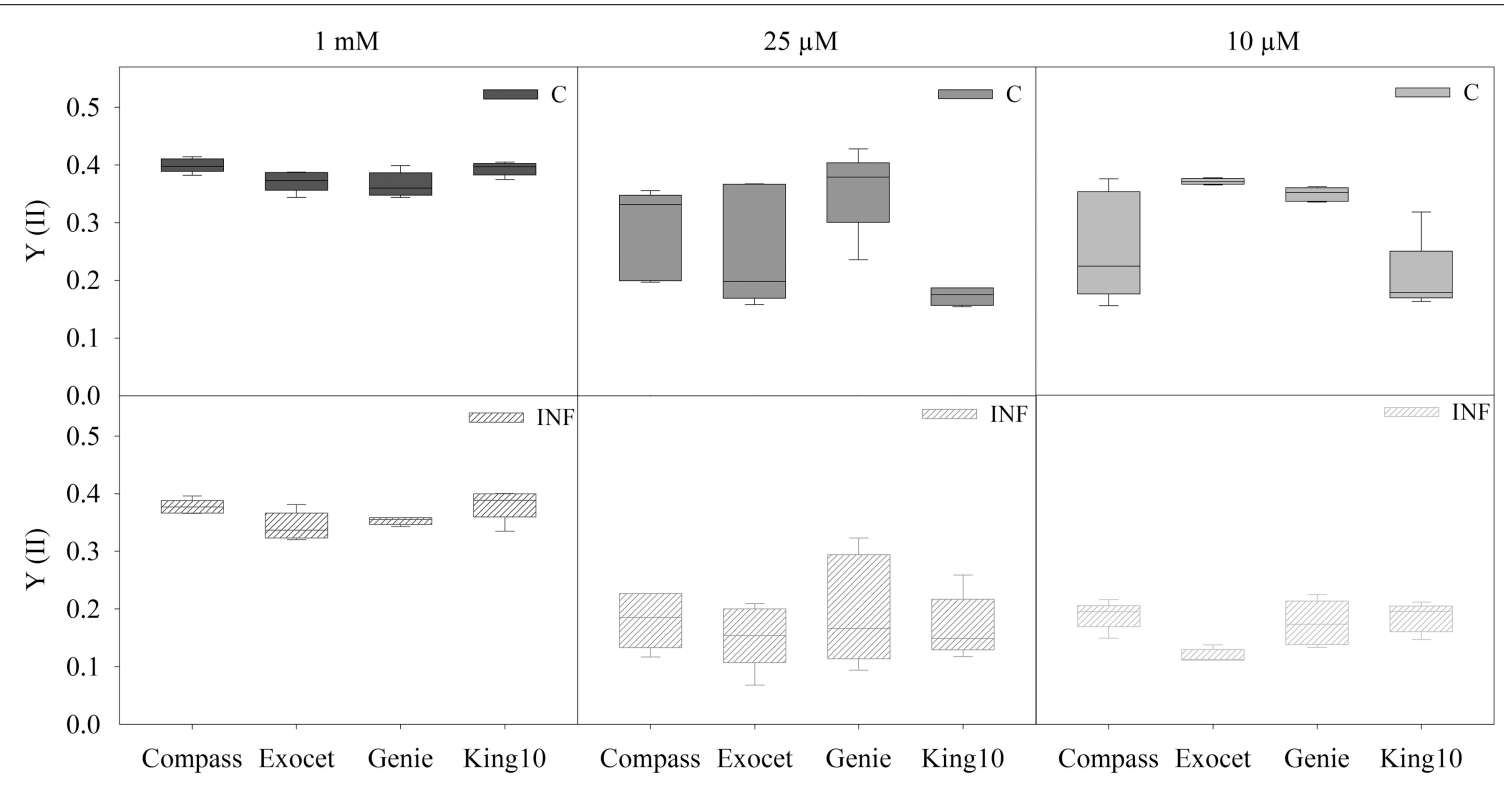

FIGURE 4 | Chlorophyll fluorescence. The chlorophyll fluorescence measurements were done by PAM imaging. Five plants (five leaves fully expanded) per sulfate application and pathogen treatment (described for Figure 2) were determined by calculating the yield (YII) out of two areas of interest (AOI). The performances were obtained for $10 \mathrm{~min}$ after $20 \mathrm{~min}$ of dark adaptation. Data are represented as box plots. Filled boxes present non-infected plants $(\mathrm{C})$ and striped boxes the corresponding results of infected plants (INF) phosphorus are common and frequently limit canola yields (Prabhu et al., 2007).

The plants of the cultivars incorporated under control con-

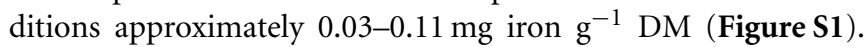
Apart from a few sample values, the iron content decreased in plants fed with less sulfur except in the cultivar Compass. The highest amounts of iron were measured in the plants fed with $1 \mathrm{mM}$ sulfate in King10 (0.06-0.11 $\mathrm{mg}$ iron $\left.\mathrm{g}^{-1} \mathrm{DM}\right)$. The iron content increased by $16.5-63 \%$, due to infections in all cultivars.

In the cultivars, only slight differences were observed in the phosphorus content (Figure S1). Exocet showed the highest phosphorus values without big fluctuations. In Genie plants, the phosphorus in $\mathrm{mg} \mathrm{g}^{-1} \mathrm{DM}$ increased in the plants fed with 


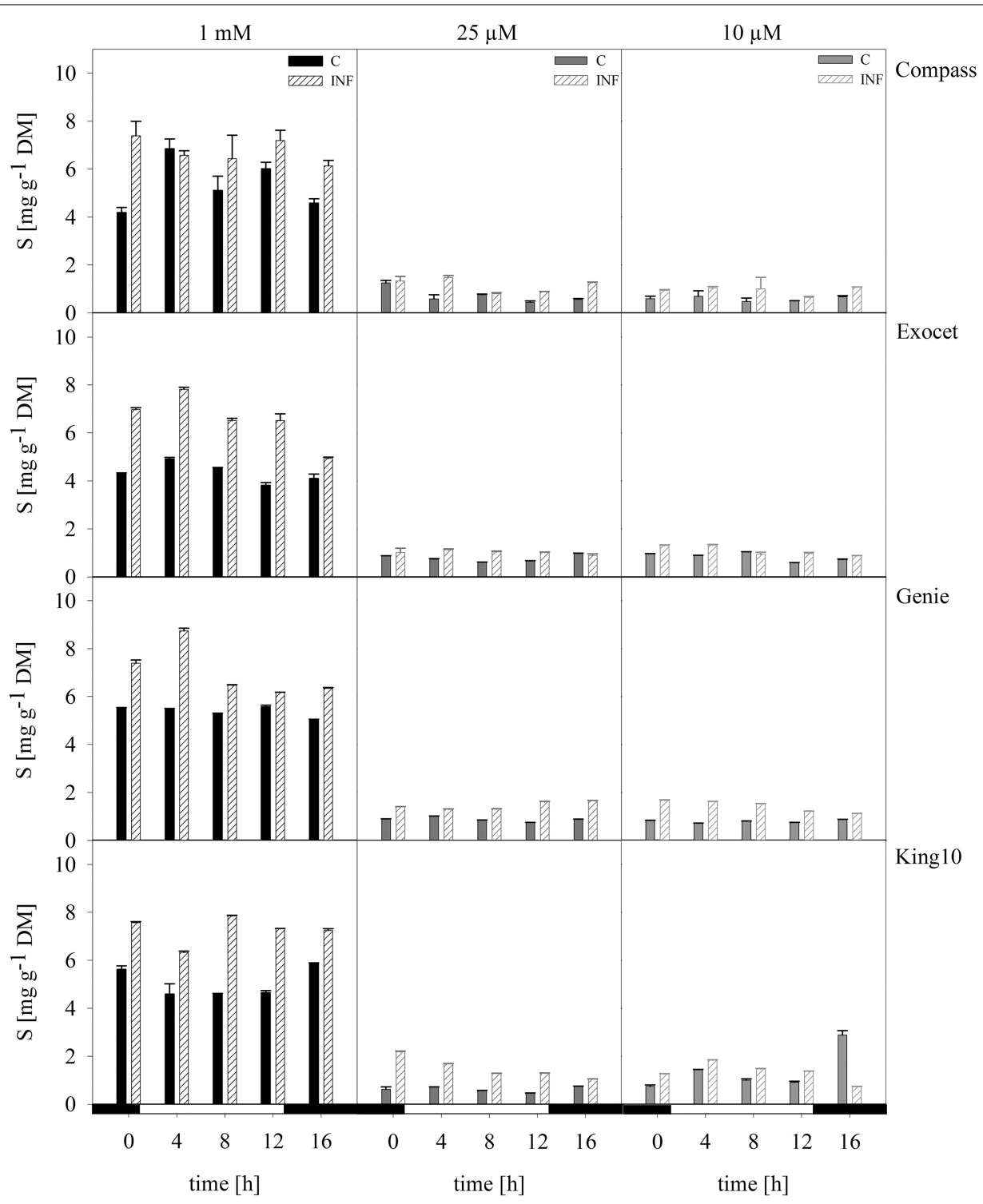

FIGURE 5 | Elemental sulfur. The elemental sulfur was measured in dried plant material by ICP-OES. Seven-day-old seedlings of the cultivars were mock-inoculated or infected with $V$. longisporum spores. Plants were grown under full sulfur supply $\left(1 \mathrm{mM} \mathrm{MgSO}_{4}\right)$ and under sulfur limitation $\left(0.025 \mathrm{mM}\right.$ and $\left.0.010 \mathrm{mM} \mathrm{MgSO}_{4}\right)$ in a climate chamber for 14 dpi. Three plants with five leaves fully expanded per treatment were harvested in a diurnal rhythm every $4 \mathrm{~h}$ starting $1 \mathrm{~h}$ before light was switched on (0-16h). For measuring the material was dried. Data calculated as $\mathrm{mg} \mathrm{g}^{-1}$ DM represent the mean of three dependent technical replicates $\pm \mathrm{SD}$. Filled bars represent the mock-inoculated plants (C) grown with $1 \mathrm{mM}$; 0.025 or $0.01 \mathrm{mM} \mathrm{MgSO}_{4}$ and the striped bars show the corresponding results of infected plants (INF).
$0.025 \mathrm{mM} \mathrm{SO}_{4}^{2-}$. The values in the line King10 remained without high fluctuation; the content of phosphorus increased under the condition of sulfur limitation in non-infected plants.

As a tendency, Compass showed less incorporated phosphorus compared to the other cultivars. The measurements furthermore showed hints that the phosphorus content in infected plants increased.

\section{Sulfate}

The anion sulfate which is taken up by the roots was measured in leaves from non-infected and infected plants using capillary electrophoresis. In the samples from plants grown with 0.025 and $0.01 \mathrm{mM} \mathrm{MgSO}_{4}$, the sulfate contents were below the detection limit of the method used. Exemplary for dark and light conditions, the amount of sulfate, given in $\mu \mathrm{mol} \mathrm{g}{ }^{-1} \mathrm{FM}$, was analyzed at 0 (dark) and $4 \mathrm{~h}$ (light) in control and infected plants (Figure 6). For non-infected plants of the three varieties, an increase in the sulfate amount from the harvesting time point in the dark to the harvesting time point in the light was measured, whereas in line King10 the sulfate content slightly decreased. At 0 and $4 \mathrm{~h}$, Genie showed the highest values with 10.93 and $13.14 \mu \mathrm{mol} \mathrm{g}^{-1} \mathrm{FM}$, respectively. An increase in the 


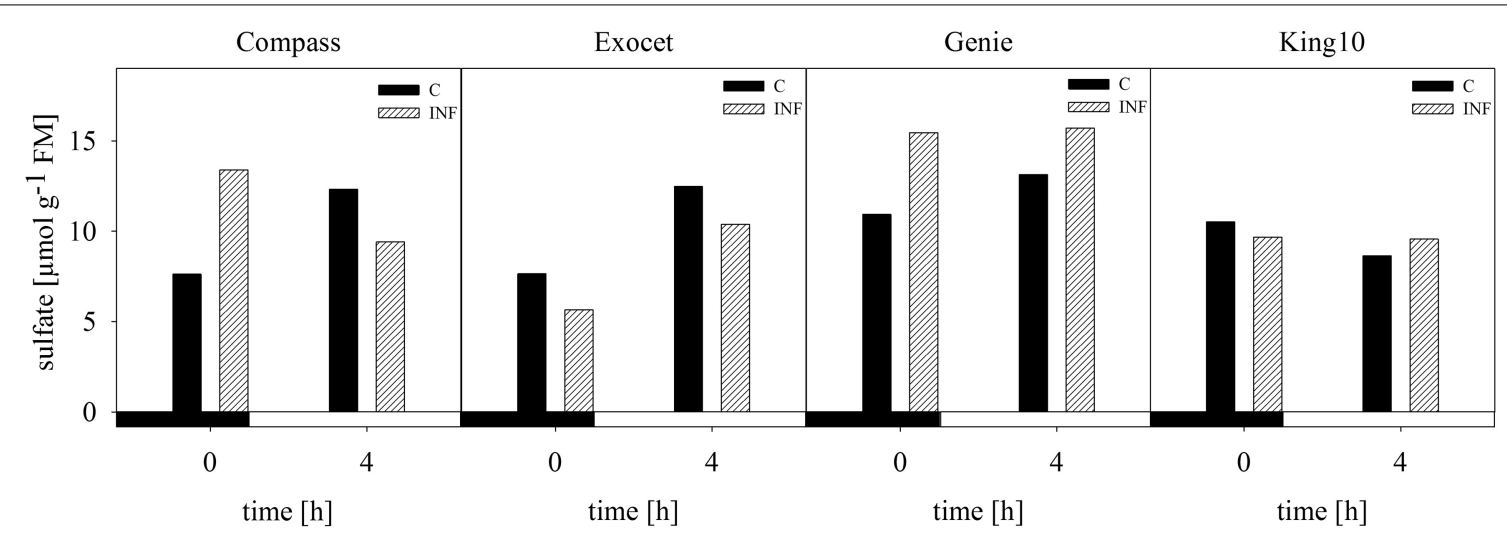

FIGURE 6 | Determination of sulfate. Sulfate content was measured by using capillary electrophoresis. Leaf material from non-infected and infected plants with five leaves fully expanded grown with $1 \mathrm{mM} \mathrm{MgSO}_{4}$ and collected at 0 and $4 \mathrm{~h}$ was used. Sulfate amount was calculated in $\mu \mathrm{mol} \mathrm{g} \mathrm{g}^{-1}$ FM and data represent the result of one measurement. Filled bars represent the control plants $(\mathrm{C})$ and striped bars indicate infected plants (INF). sulfate content in infected Compass and Genie plants at $0 \mathrm{~h}$ up to 43 and 30\% was observed. In contrast, Exocet and King10 did not show any increase of sulfate in infected plant at $0 \mathrm{~h}$. In Genie, the highest amounts of sulfate (about $16 \mu \mathrm{mol} \mathrm{g}^{-1} \mathrm{FM}$ ) were observed after infection, both in light and dark.

\section{Thiols}

The compounds cysteine and glutathione, which contain reduced sulfur, were analyzed in control and infected plants by HPLC. Under full sulfur, supply an increase in the cysteine content was measured ranging from 11.25 up to $27.52 \mathrm{nmol} \mathrm{g}^{-1} \mathrm{FM}$ over the day. Highest amounts were observed after $8 \mathrm{~h}$, and lowest amounts at 0 and $16 \mathrm{~h}$ (Figure 7 ). When comparing the amounts of cysteine among the cultivars, Exocet accumulated with full sulfur supply the highest amounts of cysteine. In plants grown under sulfur limitation, the cysteine content decreased by more than $30 \%$. The lowest levels were obtained in the middle of the light phase. The glutathione content showed similar fluctuations over the day. However, the decrease under sulfur limitation by up to $90 \%$ is more drastic.

In infected plants grown under full sulfur supply, the amounts of cysteine and glutathione increased only slightly. Under sulfur deficiency, more cysteine and glutathione is accumulated in the leaves of infected plants. Among the cultivars, King10 showed the highest amounts of accumulated thiols in leaves of infected plants. After $8 \mathrm{~h}$, the plants of King10 accumulated up to $40 \%$ more cysteine than the control plants under sulfur deficiency. Infected plants of King10 accumulated three times more glutathione than control plants.

\section{Phenols and flavonoids}

Total phenols. Phenolic compounds are bioactive components and are discussed to have high health-promoting activity. The content and composition of phenolic compounds can be used to distinguish among plant cultivars and varieties (Klepacka et al., 2011). Figure 8 shows the phenolic contents of the cultivars. The results of the control plants showed that they accumulated the highest amounts of phenolic acids. Only slightly decreasing amounts were observed in plants grown under sulfur deficiency.
The control plants of the cultivar Genie showed thereby the lowest levels (Figure 8). In infected plants, the phenolic levels were reduced independently of the sulfur supply.

Total flavonoids. Measurements of the total flavonoid content (Figure S2) showed that there were only slight differences. The values ranged between 0.6 and $1.4 \mu \mathrm{g}$ catechin equivalent per $\mathrm{mg}$ FW. Interestingly, in the plants of Genie, the control plants showed more accumulated flavonoids than infected plants, independently from the amounts of sulfur applied. By contrast, King10 showed the lowest flavonoid levels in the control plants and under sulfur limitation $\left(0.025 \mathrm{mM} \mathrm{MgSO}_{4}\right)$, the infected plants produced more flavonoids than the control plants.

Anthocyanins. Anthocyanins are a subgroup of the flavonoids. The values range between 0.56 and 3.45 absorption units (AU) of anthocyanins per g FM for the control plants (Figure 9). The lowest levels were determined in the control plants (0.56-1.37 AU $\left.\mathrm{g}^{-1} \mathrm{FM}\right)$. Plants grown under sulfur limitation showed increased levels. Notably, Exocet reached the highest values.

Infected plants especially from Exocet and Genie showed no differences to control plants at full sulfur supply. The anthocyanin levels increased only slightly under sulfur limitation. With less sulfur, the anthocyanin levels in King10 and Compass increased, but only in Compass the amounts exceed the levels of the noninfected plants at time points 12 and $16 \mathrm{~h}$.

\section{NORTHERN BLOT ANALYSIS}

To analyze the key steps of sulfur assimilation in the oilseed rape cultivars, the expressions of sulfate transporter 4;2 (SULTR4;2), and two $A P R$ genes were determined (Figures $10 \mathrm{~A}-\mathrm{C}$, Figure S3). As an indicator for sulfur-induced stress the expression of SULTR4;2 was analyzed (Parmar et al., 2007). In addition, this is the only transporter expressed in leaves that rapidly responds to S deficiency (Buchner et al., 2004b). Only under sulfur limitation did the expression of the tonoplast-localized SULTR4;2 increase strongly, indicating that $S$ fertilization in our experiments is sufficient. The highest degree of up-regulation was detected in Compass. Light seemed to influence the expression 

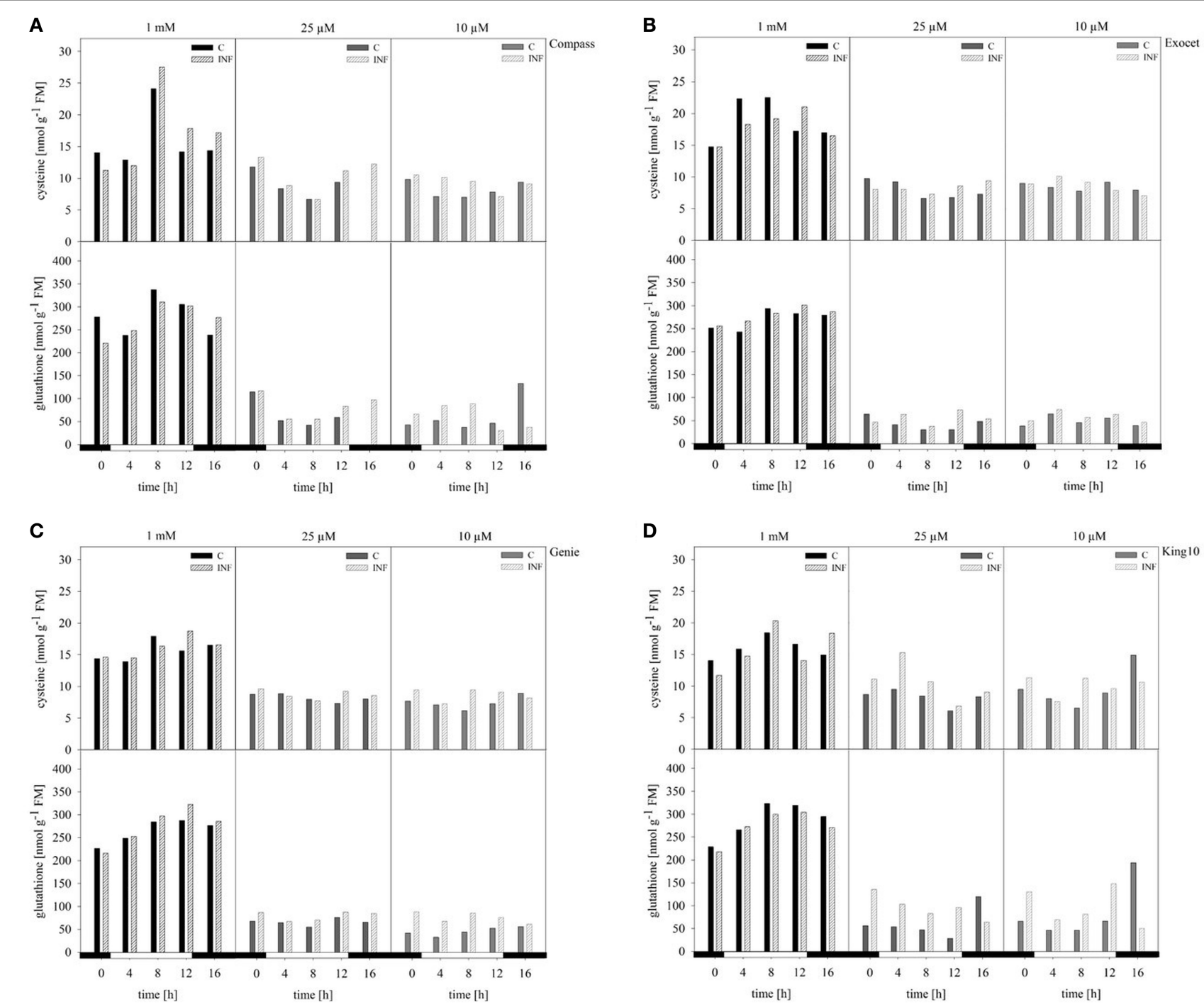

FIGURE 7 | Thiol contents. The cysteine and glutathione contents were determined in plants (five leaves fully expanded) treated and collected as described for Figure 5 by HPLC. The thiol contents were calculated in nmol

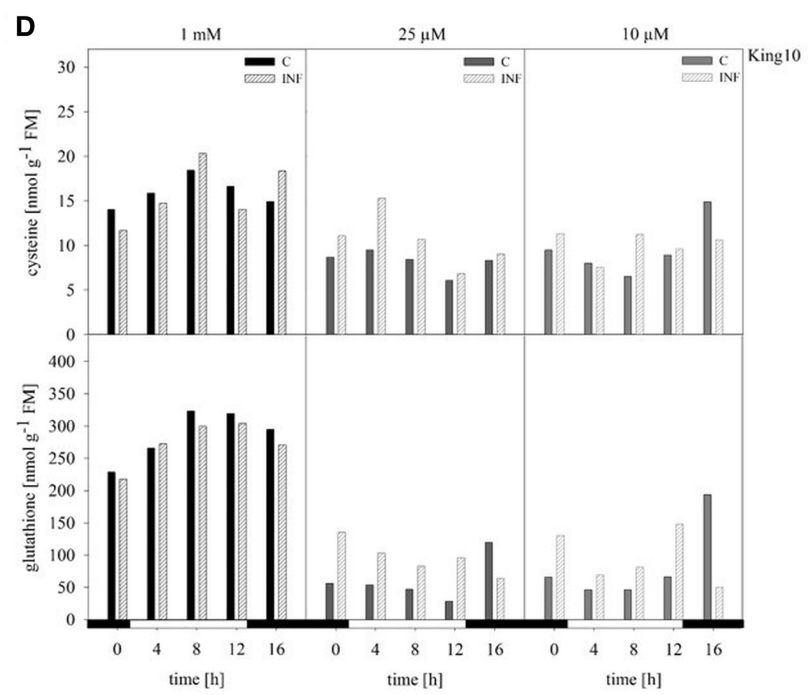

$\mathrm{g}^{-1} \mathrm{FM}$ in the cultivars (A) Compass, (B) Exocet, (C) Genie, and (D) King10. Filled bars represent the control plants $(C)$ for different sulfur fertilization and striped bars indicate infected plants (INF).

slightly in the time range 3-7 h after light was switched on. Described as one of the primary regulatory points in sulfate reduction, adenosine $5^{\prime}$-phosphosulfate (APS) is reduced to sulfite catalyzed by APS reductase. Therefore, the homologs of both APR2 and APR3 were analyzed because both isoforms reveal a different expression behavior in A. thaliana (Kopriva et al., 1999). In B. napus, the expression of both genes was influenced by the sulfur status of the plants. Under limitation, the $A P R$ expression increased in all cultivars. The lowest degree of up-regulation was detected for $A P R 2$ in Compass, the most in Genie. Regarding the expression of $A P R 3$, the highest increase under sulfur limitation was determined in King10.

In the experiments, the expression of BnSULTR4;2 is affected by the pathogen. Especially under sulfur limiting conditions, the expression decreased, most strongly in Compass. The pathogen controls the expression of $A P R 2$ in the following intensity order:
Compass, Exocet and Genie. The line King10 showed higher expression levels of APR2 than Genie, but here the expression is clearly up-regulated in infected plants. In the case of the expression pattern of $A P R 3$, in Genie and King10 the highest expressions in infected plants were detected $3 \mathrm{~h}$ after light was switched on. The difference among the APR 3 expression in infected and non-infected plant was higher in King10 than in all other cultivars.

\section{ANALYSIS OF THE AMPLIFIED DNA FRAGMENTS OF B. napus GENES}

The analysis of the four different $B$. napus cultivars revealed a number of different reactions with respect to the sulfur supply. Therefore, we investigated whether the cultivars differ in the sequences of key genes in sulfur metabolism. The respective DNA fragments of about 500 bp were amplified by PCR from the transcribed cultivar-specific cDNAs, cloned and sequenced. 


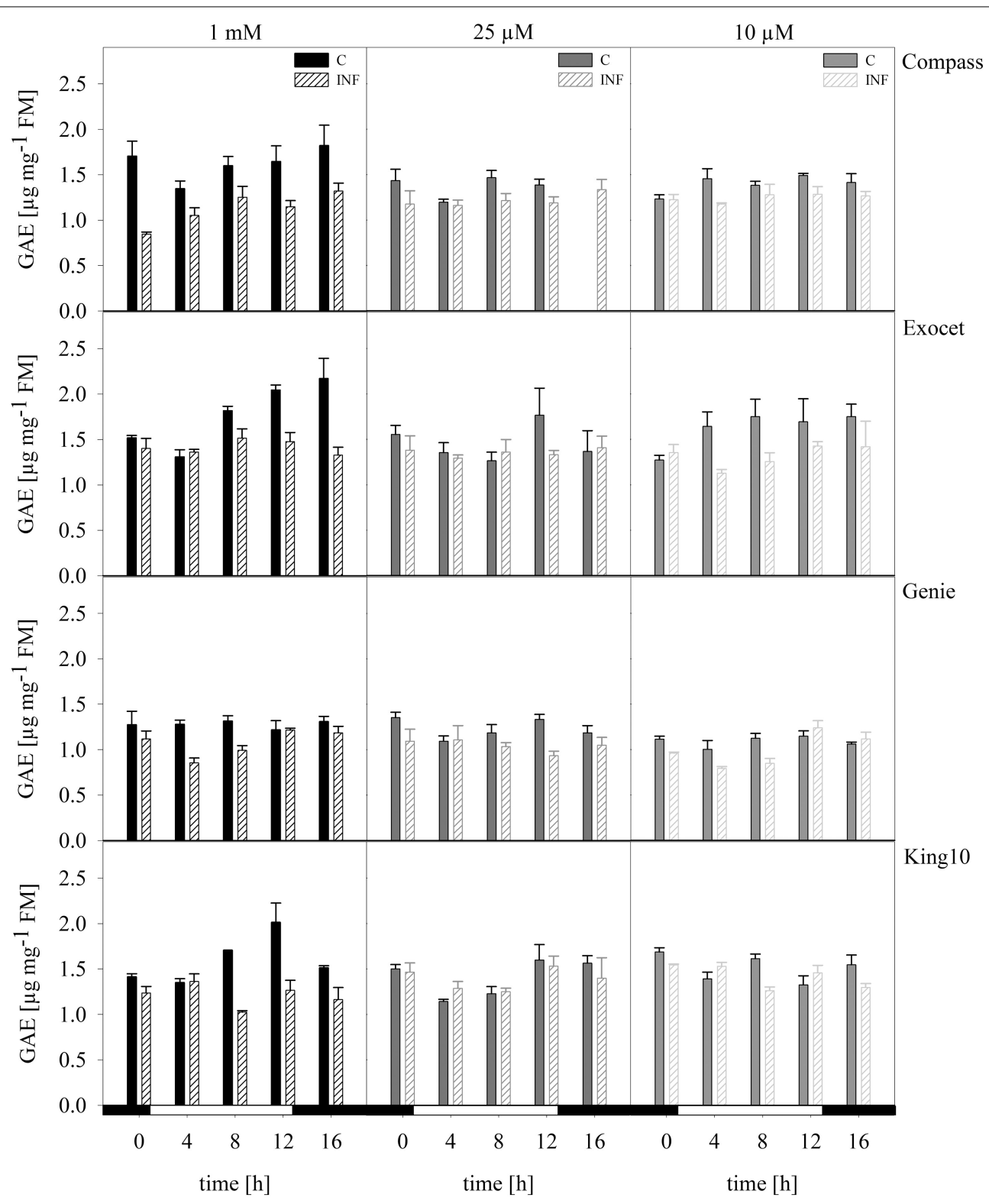

FIGURE 8 | Total phenols. The total phenol content was photometrically measured in plants with five leaves fully expanded of all cultivars. Plants for the measurement were treated and collected as described for Figure 5. The results are shown in $\mu \mathrm{g} \mathrm{g}^{-1} \mathrm{FM}$ as mean of three technical replicates $\pm S D$. For quantification gallic acid was used as a standard. Filled bars represent the control plants (C) for different sulfur fertilization and striped bars indicate infected plants (INF). GAE, gallic acid equivalent.
A considerable difference among $A P R 2$ and $A P R 3$ sequences was observed (78\%), indicating the correct choice of primer pairs for amplification of specific fragments. In comparison to the B. rapa consensus, sequences the identity was for APR2 93\% and APR3 $96 \%$, respectively. In comparison to $B$. oleracea, the identity was $100 \%$ for both, APR2 and APR3. The alignment of the APR2 and APR3 fragments from the four cultivars revealed no different bases among them. A longer fragment was amplified from the B. napus sulfur transporter SULTR4;2. The identity of the 975 bp fragment chosen was $99 \%$ between the sequences from Genie and King10. The identity of these SULTR4;2 fragments with the homologous partial sequence of the $B$. oleracea transporter was 97\% for both sequences.

\section{DISCUSSION}

\section{WHICH CULTIVARS SHOW THE HIGHEST RESISTANCE AGAINST} PATHOGEN INFECTION?

Before we can decide which cultivar is the most promising according to our results, we need to discuss first the recorded data for biomass, chlorophyll fluorescence and leaf temperature. Therefore, the best cultivar in this study is characterized by high biomass of all organs at all conditions chosen, 


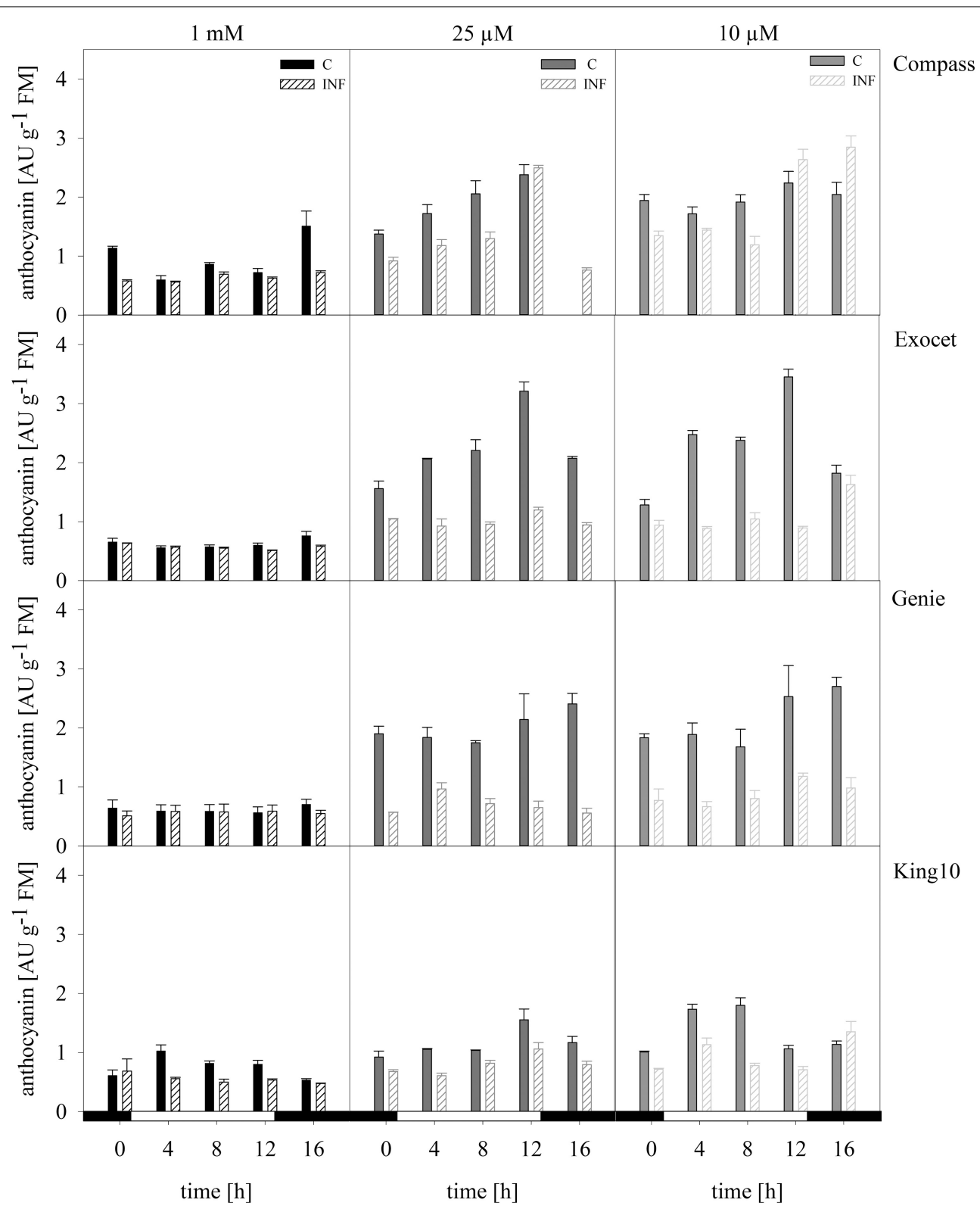

FIGURE 9 | Anthocyanins. The anthocyanins were extracted from the fresh material of plants with five leaves fully expanded treated as described for

Figure 5. The content was calculated in $\mathrm{AU} \mathrm{g}^{-1} \mathrm{FM}$ representing the mean of technical replicates, which were measured three times. Filled bars represent the control plants (C) for different sulfur fertilization and striped bars indicate infected plants (INF). AU, absorbance units. both sulfur limitation and infection by $V$. longisporum, indicating general plant health. High biomass is accompanied by comparatively low leaf temperature indicating intact stomatal closure reaction and an intact water status. The photosynthetic parameters determined should be close to the range of the controls revealing intactness of the photosynthetic apparatus. Unfortunately, quantification of the infection rate is currently not possible because fungal DNA concentrations seem to be below the detection limit, as was also reported by Enyck et al. (2009). However, biometrical parameters such as biomass reduction and PAM data clearly indicate successful infection and spreading of the fungus in the infected plants.

Compass and Exocet have the largest root system (Table 1). Our results show that Compass and Exocet have significantly longer root hairs (Figure 1). Schröder (2013) advised that highperforming plants root very deeply with a production of up to $5 \mathrm{~mm}$ long root hairs. The root hairs are essential for a better uptake of nutrients. In greenhouse experiments, a sufficient sulfur supply was added to an intact root system, resulted in a reduced fading away of roots and led to an increased efficiency of nutrient and water use (Schröder, 2013; Grierson et al., 2014). The biomass 

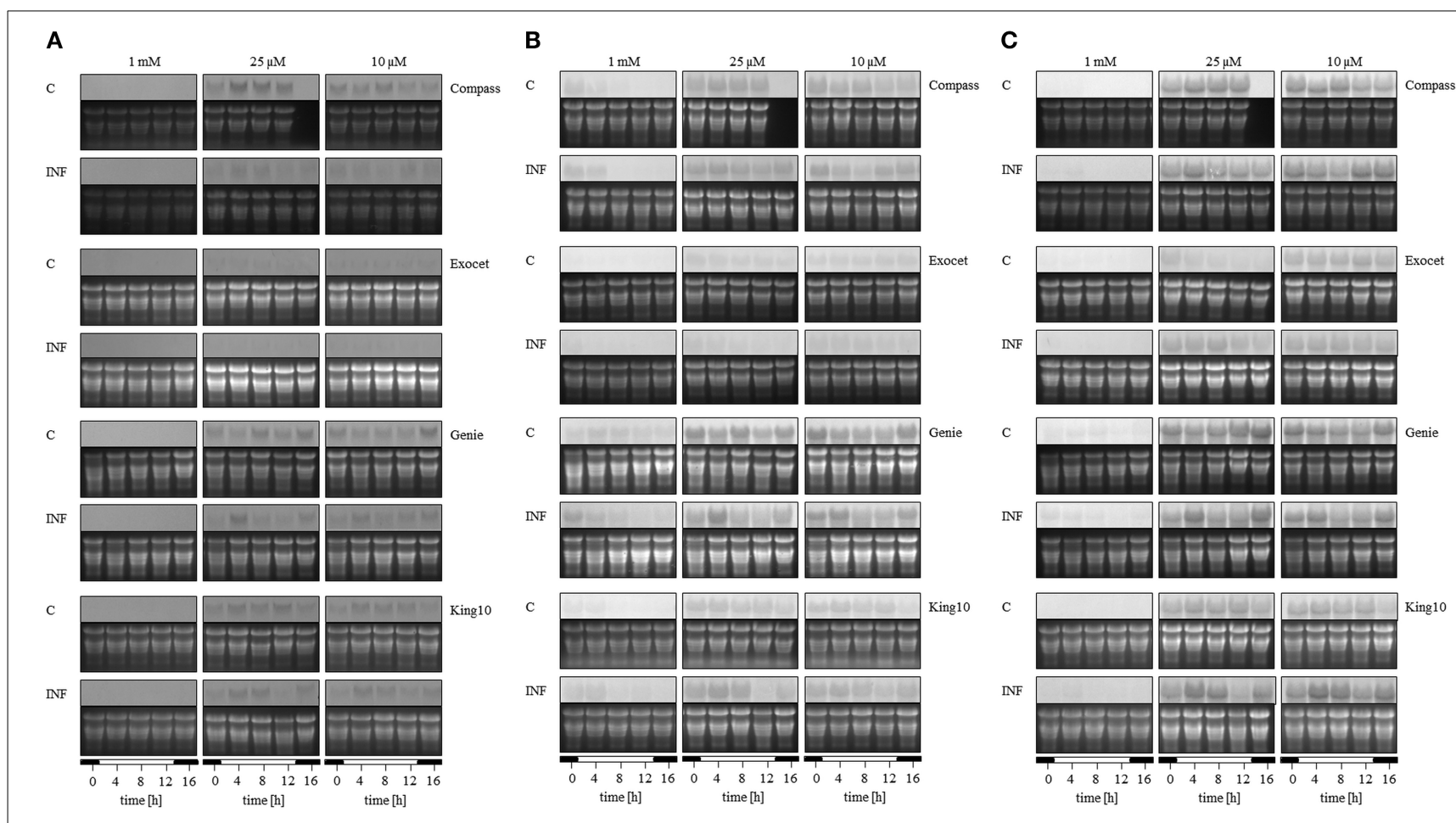

FIGURE 10 | Expression analysis. The expression of (A) SULTR4;2, (B) $A P R 2$, and (C) APR3 was analyzed by Northern blotting in plants (five leaves fully expanded) treated and collected as described for Figure 5. Total RNA were isolated and transferred onto membranes. The detection of mRNA was done with probes labeled with digoxigenin. Abbreviations for probes: $A P R$, adenosine phosphosulfate reductase; SULTR, sulfate transporter. measurements in this study are in agreement with these observations (Figure 2). With full sulfur supply, cultivars Compass and Exocet showed the highest leaf biomass. Under sulfur limitation, non-infected plants of both cultivars showed also the highest leaf biomass (data not shown). However, for all cultivars a significant reduction of DM and shoot to root ratio was obtained under sulfur limiting conditions. Interestingly, in previous experiments, it was shown that the fungus had no influence on the shoot to root ratio but only on the total DM of the plants after $14 \mathrm{dpi}$ as described in Enyck et al. (2009). In experiments done with $B$. napus and $V$. longisporum, the fungus did not overcome the hypocotyl barrier until $21 \mathrm{dpi}$, although the plants showed massive stunting of the stem and mild leaf chlorosis. A significant decrease of stem biomass was observed after $28 \mathrm{dpi}$ (Floerl et al., 2008). In experiments done with more than 30 high-performance oilseed cultivars, it also was shown that $V$. longisporum influenced the plant growth. Infected cultivars showed reduced plant growth compared with control plants (Burlacu et al., 2012). However, in experiments we performed with plants grown for 21 day under sulfur deficiency and infection (21 dpi) showed very strong stress symptoms; therefore we disregarded these measurements and decided to analyze under the conditions described in this study. According to our results, Exocet seems to be more susceptible to fungal infections, whereas the biomass of Compass suggests to be the best performing cultivar.

Baker and Rosenqvist (2004) concluded that the reduction of sulfur levels in sugar beet had to reach sulfur starvation level before any changes were detectable in chlorophyll fluorescence parameters, e.g., in $\mathrm{F}_{\mathrm{v}} / \mathrm{F}_{\mathrm{m}}$. That leads us to the conclusion that our plants were grown only under sulfur limitation, and not sulfur starvation, and the influence on the maximum quantum yield remained low. Interestingly, the photosynthetic performance of King10 is significantly reduced under sulfur limitation. In contrast, the general fitness of Genie was influenced less by sulfur limitation as demonstrated by steady activities of the photosystems (Figure 4). However, after fungal infection the quantum yield in photosystem II was significantly reduced under sulfur limitation in all cultivars. It was shown before that the quantum yield of the photosystems decreased in plants infected with $V$. longisporum, but neither the nitrogen nor the sulfur or phosphorus amounts accumulated differently in non-infected and infected plants (Floerl et al., 2008). In conclusion, the fungus $V$. longisporum did not influence the photosynthetic activity of the plants under full sulfur supply. These results confirm the principle idea of SED (Rausch and Wachter, 2005). The sulfur status did not influence the leaf temperature significantly. Compass, Exocet and Genie, have a lower leaf temperature than the control plants when additionally infected with V. longisporum. At decreased applied sulfur amounts, the temperature was slightly higher, at least at $0.025 \mathrm{mM} \mathrm{MgSO}_{4}$. In experiments performed by Muneer et al. (2014) with 8-week-old B. napus plants grown under different sulfur supply for 5 or 10 day, the stomata were closed under sulfur limitation. Photosynthesis rates and stomatal conductance were decreased. Previously, it was observed that plants suffering from (abiotic) stress have a higher leaf temperature than non-stressed control plants (Guretzki and Papenbrock, 2013). Obviously, the 
thermographic analysis reveals different results, depending on stress and environmental conditions, but often leads to a clear differentiation between control and treatment.

\section{WHAT IS THE ROLE OF SULFUR, SULFATE AND SULFUR-CONTAINING COMPOUNDS IN VERTICILLIUM DEFENSE?}

Interestingly, the sulfur content itself was generally higher in infected plants than in non-infected plants, independent on the cultivar, indicating a specific increase of sulfur uptake and accumulation induced by pathogen attack. Looking at the accumulated total sulfur, line King10 incorporated the highest amounts of sulfur, in particular, after infection and under low sulfur application (Figure 5). Although the variety Genie performed worst compared to the other cultivars, it incorporated high amounts of sulfur, especially in non-infected plants, and in the same range as King10. All cultivars showed fluctuations of the sulfur content, especially Compass with full sulfur supply. Results from Huseby et al. (2013) showed a diurnal regulation of the sulfate uptake and reduction which corresponds with our results. Especially, the large increase in total sulfur contents at the beginning of the light phase is remarkable. The contents were analyzed several times in various experimental set ups and also by other experts (data not shown), resulting in consistent results. One could speculate that sulfate is taken up at the beginning of the light phase, reduced, and then later superfluously reduced sulfur is released as volatile compounds, such as sulfide, via the leaves and also via the soil. However, these assumptions need further investigation. An accumulation of elemental sulfur in the xylem vessels of tomato plants infected by $V$. dahliae was reported by Williams et al. (2002). Our results indicate an accumulation of total sulfur in $B$. napus leaves after infection with $V$. longisporum. Are these accumulations of total sulfur an indication for comparable defense strategies in both plant-pathogen systems? These results further support the hypothesis of SED.

Results from Huseby et al. (2013) showed a diurnal regulation of the sulfate uptake and reduction which corresponds with our results. In our results, the sulfate content was higher in light than in the darkness. The factor light outweighs the factor infection (Figure 6). In parallel, the expression of the sulfate transporter BnSultr4;2 was increased during sulfur-limiting conditions with a maximum degree of expression during the light period (Figure 10A). It is clear that sulfate was taken up during periods of active photosynthesis. It was shown previously in experiments done with 4-weeks-old B. napus plants, that due to the sulfur limitation, the sulfate concentrations decreased at variable rates, at first in roots and young leaves, then in the middle leaves, and later in the oldest leaves. In parallel the sulfate transporter BnSultr4;2 was first expressed in roots and in young leaves (Parmar et al., 2007). Interestingly, in our system, the expression of the sulfate transporter BnSultr4;2 was influenced by the pathogen. However, in contrast to our expectations in all cultivars the mRNA levels of BnSultr4;2 were lower in infected plants than in non-infected plants. In the context of SED higher mRNA levels of BnSultr4;2 were expected due to a higher demand for sulfate and subsequent biosynthesis of sulfur-containing defense compounds. One could postulate that V. longisporum directly influences the plant's gene expression to prevent availability of sulfate, a prerequisite for the induction of SED. That needs to be investigated in future experiments.

Even though we do not know the full sequence of the isoforms of $A P R$ in $B$. napus, our results implied that the mRNA levels of $B n A P R 2$ are more strongly regulated by light than the levels of $B n A P R 3$, especially visible in Genie under sulfur-limiting conditions. These results are in agreement with results obtained by Kopriva et al. (1999) and Huseby et al. (2013): Both the expression of three $A P R$ isoforms and of APR enzyme activity are diurnally regulated and by sulfate availability. In our experiments, the expression of both $A P R$ isoforms are differently regulated by sulfate and light, and in addition $V$. longisporum infection influences expression either positively or negatively. As was shown by Wang et al. (2011) bacterial infection leads to a reprogramming of the diurnal rhythm and even the circadian clock on expression level. Effects of fungal infections on the genes involved in continuance of diurnal and circadian rhythms need to be further investigated.

With the sulfate assimilation, a co-regulation of the GSL was described (Huseby et al., 2013). GSL act as typical sulfurcontaining compounds in Brassicaceae against herbivores and insects occurring in the soil (Halkier and Gershenzon, 2006). Interestingly, experiments done with a fungal pathogen and a Brassicaceae as host generated indication that crude GSL extracts or detached leaf material act defensively (Buxdorf et al., 2013; Witzel et al., 2013). In the $A$. thaliana accessions investigated by Witzel et al. (2013), the total GSL concentrations were about 10 times higher than in our $B$. napus cultivars, where the maximum concentration of total GSL in the leaves was less than $4 \mu \mathrm{mol} \mathrm{g}^{-1}$ TM (data not shown). The most effective GSL with respect to fungal growth inhibition in A. thaliana was 2-propenyl GSL that is not present in B. napus or can at least not be detected in leaves. In addition, the inhibiting concentration reported by Witzel et al. (2013) of single GSLs would probably not be high enough to reduce the fungal growth rate in our $B$. napus cultivars. Therefore, for the situation in B. napus the results by Witzel et al. (2013) are not applicable and relevant. In summary, based on these results and calculations we assume that even if the GSL contents and their composition would differ in the B. napus 00 cultivars in high and low sulfur cultivation, we would not see any influence on fungal growth. The role of GSL and their breakdown products in the defense against fungal pathogens needs to be investigated in more detail in vivo.

The sulfur-containing glutathione is an important stress indicating metabolite. There are numerous examples that oxidative stress reduces the overall concentration of glutathione, but particularly the concentration of reduced glutathione (GSH). One would expect that after a pathogen attack, the concentration of total glutathione and GSH is drastically reduced. However, there are several examples that this is not the case. For example, an increase of the cysteine and glutathione content was measured in field grown $B$. napus plants due to infection with Pyrenopeziza brassicae (Bloem et al., 2004). There is a reduction in GSH observed, but it is not as drastic as one would expect from abiotic stress effects (Cooper et al., 1996; Bloem et al., 2004; Bollig et al., 2013). These results are in agreement with our results. Furthermore, the cysteine content was measured. As a precursor of defense compounds (Smith and Kirkegaard, 2002; Van Wees 
et al., 2003; Rausch and Wachter, 2005), a decrease of the cysteine content in infected plants is expected. According to results of infected A. thaliana plants (Álvarez et al., 2011), a decrease of about $25 \%$ in the cysteine content was measured. In comparison to our results, this observation is not supported. In contrast, the content seems to be slightly increased in infected plants. Fluctuations in the content over the day for glutathione and cysteine make an evaluation even more difficult. In conclusion, our results show that the cysteine and glutathione content is more influenced and increased by the light conditions than by pathogen attack.

In experiments of Blake-Kalff et al. (1998), the glutathione concentration decreased in plants when grown under sulfur deficiency during the whole course of the experiment and the glutathione content decreased more rapidly grown on either 0.02 or $0.100 \mathrm{mM}$ sulfate. In leaves of plants grown under sulfur limitation, the sulfur content was strongly negatively affected. Alternatively, the sulfur content increased in roots. This could also be observed under full sulfur supply. About $50 \%$ of the energy obtained by photosynthetic activity is transported into the B. napus root systems (Agrios, 2005).

\section{WHICH CULTIVAR PERFORMED BEST UNDER SULFUR LIMITATION AND PATHOGEN INFECTION? RECOMMENDATION FOR CHOOSING A ROBUST CULTIVAR}

The phosphorus contents were always higher in infected plants (about 15\%). The results indicate that phosphorus, as one of the macronutrients of the plants with $0.2-0.6 \%$ of DM and necessary for the energy metabolism in organisms, plays an important role in pathogen defense, probably due to increased energy demand. Based on the fact that increased phosphorus or nitrogen concentrations have also been reported in other Verticillium-infected plants like tomato and Arabidopsis, the authors suggested that there is a yet unknown interference of Verticillium with the phosphorous or nitrogen metabolism (Floerl et al., 2008). High phosphorus amounts could lead to a decrease in disease but also to an increase in disease after fungal infection (Prabhu et al., 2007). The influence of phosphorus remains unexplained, therefore, high phosphorus values, especially in Exocet after infection, are not discussible.

Iron, essential for biological activity of many proteins mediating electron transfer and redox reactions, is influenced due to infection. Experiments with different pathogens and crop plants revealed an influence of the iron status on the host-pathogen relationships in different ways by affecting the pathogen's virulence as well as the host's defense. Arabidopsis plants, infected with Erwinia chrysanthemi, developed an iron-withholding response that involved a change of the iron distribution and trafficking (summarized in Expert et al., 2012). The infection could lead to the release of root exudates for iron mobilization. These observations could be also an explanation for our results especially for the line King10.

In experiments done by D'Hooghe et al. (2013) 2-month-old oilseed rape plants were transferred to sulfur limiting conditions. In these experiments, the total shoot biomass was not significantly reduced, but the growth and the photosynthesis rate were inhibited. The increase of the anthocyanins and the $\mathrm{H}_{2} \mathrm{O}_{2}$ content in sulfur insufficient plants were explained with means of oxidative stress. No significant differences in the chlorophyll and flavonol contents were detectable (D'Hooghe et al., 2013). Prabhu et al. (2007) described that fungistatic substances like phenolic compounds and flavonoids accumulate in epidermal cells of leaves, stems, and roots after infection. We could observe this phenomenon only in line King 10.

The accumulation of phytoalexins settled $48 \mathrm{~h}$ after inoculation and was accompanied by a more rapid increase in the rate of anthocyanin accumulation. The results suggest that the plant represses less essential metabolic activities, such as anthocyanin synthesis, in order to compensate the immediate biochemical and physiological needs for the defense response (Lo and Nicholson, 1998). According to our results King10 seems to be unaffected by sulfur limitation and infection.

Oilseed rape hybrids have up to $10 \%$ higher yields than conventional lines such as King10. The first hybrid cultivars were market-launched in Germany in 1995. Since that time, there has been a discussion which plant performs best: hybrids or bredlines (Alpmann, 2009). Actually, in our experiments under highly controlled conditions, the hybrid Genie and the line King10 performed equally well with respect to all conditions chosen: to sulfur limitation, reaction to infection, and uptake of nutrients (Figure S1).

In 2010, the cultivars Compass and King10 were mentioned as best performing cultivars with high oil contents (DSV). The oil content has a major influence on the market performance, which depends on the cultivar. Cultivars with high oil content are more attractive with increasing prices for oilseed rape. Already one percent more oil content is paid with a $1.5 \%$ higher fee (Alpmann, 2009). Therefore, already in early phases of development general plant fitness and plant health need to be carefully checked to obtain finally high seed yields. In the future, the performance in later phases of the development and finally the seed yield, oil content, and composition need to be studied. Then a recommendation with respect to moderate sulfur limitations and pathogens such as $V$. longisporum could be given. In conclusion, our results indicate that line King10 is the most promising cultivar: Under sulfur deficiency and after infection, line King10 had higher contents of flavonoids and accumulated more sulfur. However, one has to keep in mind that the determination of the biomass of 3 -weeks-old plants may not have any correlation to the final yield but early stage changes could be predictive of the further development and the following loss in yield.

\section{ACKNOWLEDGMENTS}

We gratefully acknowledge the Deutsche Saatveredelung AG, Lippstadt, Germany, for providing us with seeds of the different Brassica napus cultivars and Dr. Nadine Riediger, University Göttingen, Germany, for providing us with Verticillium longisporum. We would like to thank Pamela von Trzebiatowski and Julia Volker for technical assistance and the gardeners Yvonne Leye and Lutz Krüger for taking care of the plants. We also would like to thank Dr. P. Buchner and Dr. M. Hawkesford, Rothamsted, UK, for advice at the beginning of the project. Anna Terentschenko and Eike Schöndube, Hannover, established some of the cultivation methods during their BSc theses. We acknowledge support by 
Deutsche Forschungsgemeinschaft and Open Access Publishing Fund of Leibniz Universität Hannover.

\section{SUPPLEMENTARY MATERIAL}

The Supplementary Material for this article can be found online at: http://www.frontiersin.org/journal/10.3389/fpls.2015.00009/ abstract

\section{Figure S1 | Measurement of iron and phosphorus by ICP-OES. The} elements iron (A) and phosphorus (B) were measured in dried plant material by ICP-OES. Dried material from plants with five leaves fully expanded and treated as described for Figure $\mathbf{5}$ were used. Data calculated as $\mathrm{mg} \mathrm{g}^{-1}$ DM represent the mean of three dependently technical replicates \pm SD. Filled dots represent the mock-inoculated plants (C) and open dots show the corresponding results of infected plants (INF).

Figure S2 | Total flavonoids. The total flavonoid content was photometrically measured in the cultivars with five fully expanded leaves treated as described for Figure 5. The results are given in $\mu \mathrm{g} \mathrm{g}^{-1} \mathrm{FM}$ as mean of three technical replicates $\pm S D$. For quantification catechin was used as a standard. Filled bars represent the control plants (C) for different sulfur fertilization and striped bars indicate infected plants (INF). CE، catechin equivalent

Figure S3 | Expression analysis. Results of Northern Blot analysis (Figure 10) were evaluated with the program GelAnalyzer (GelAnalyzer.com). Intensity for each band detected on the membrane was calculated in reference to the first sample $(0 \mathrm{~h})$. Data represent the relative expression in \%. Values of non-infected plants with $1 \mathrm{mM} \mathrm{MgSO}_{4}$ at $0 \mathrm{~h}$ were used as $100 \%$ for control and infected plants for each cultivar. (A) SULTR4;2, (B) APR2, and (C) APR3. Filled dots represent the mock-inoculated plants $(C)$ and open dots show the corresponding results of infected plants (INF)

\section{REFERENCES}

Agrios, G. N. (2005). Plant Pathology. Waltham: Academic Press.

Ahmad, A., and Abdin, M. Z. (2000). Photosynthesis and its related physiological variables in the leaves of Brassica genotypes as influenced by sulphur fertilization. Physiol. Plant. 110, 144-149. doi: 10.1034/j.1399-3054.2000.110119.x

Allègre, M., Hamilton, J. G., Resti, J. P., Zangerl, A. R., Berenbaum, M. R., and DeLucia, E. H. (2007). Stomatal deregulation in Plasmopara viticolainfected grapevine leaves. New Phytol. 173, 832-840. doi: 10.1111/j.14698137.2006.01959.x

Alpmann, L. (2009). Hybride oder liniensorte? Deutsche saatveredelung, lippstadt. Innovation 3, 22-23.

Álvarez, C., Bermúdez, M. Á., Romero, L. C., Gotor, C., and García, I. (2011). Cysteine homeostasis plays an essential role in plant immunity. New Phytol. 193 165-177. doi: 10.1111/j.1469-8137.2011.03889.x

Baker, N. R. (2008). Chlorophyll fluorescence: a probe of photosynthesis in vivo. Ann. Rev. Plant Biol. 59, 9-113. doi: 10.1146/annurev.arplant.59.032607.092759

Baker, N. R., and Rosenqvist, E. (2004). Applications of chlorophyll fluorescence can improve crop production strategies: an examination of future possibilities. J. Exp. Bot. 55, 1607-1621. doi: 10.1093/jxb/erh196

Blake-Kalff, M., Harrison, K., Hawkesford, M., Zhao, F., and McGrath, S. (1998). Distribution of sulfur within oilseed rape leaves in response to sulfur deficiency during vegetative growth. Plant Physiol. 118, 1337-1344. doi: 10.1104/pp.118.4.1337

Bloem, E., and Haneklaus, S. (2002). Warum und wieviel Schwefel düngen? Institut für Pflanzenernährung und Bodenkunde, FAL Braunschweig. Innovation 1, 1-4.

Bloem, E., Haneklaus, S., Kesselmeier, J., and Schnug, E. (2012). Sulfur fertilization and fungal infections affect the exchange of $\mathrm{H}_{2} \mathrm{~S}$ and COS from agricultural crops. J. Agr. Food Chem. 60, 7588-7596. doi: 10.1021/jf301912h

Bloem, E., Riemenschneider, A., Volker, J., Papenbrock, J., Schmidt, A., Salac, I., et al. (2004). Sulphur supply and infection with Pyrenopeziza brassicae influence
L-cysteine desulphydrase activity in Brassica napus L. J. Exp. Bot. 55, 2305-2312. doi: $10.1093 /$ jxb/erh236

Bollig, K., Specht, A., Myint, S. S., Zahn, M., and Horst, W. J. (2013). Sulphur supply impairs spread of Verticillium dahliae in tomato. Eur. J. Plant Pathol. 135, 81-96. doi: 10.1007/s10658-012-0067-5

Buchner, P., Stuiver, C. E., Westerman, S., Wirtz, M., Hell, R., Hawkesford, M. J., et al. (2004a). Regulation of sulfate uptake and expression of sulfate transporter genes in Brassica oleracea as affected by atmospheric $\mathrm{H}(2) \mathrm{S}$ and pedospheric sulfate nutrition. Plant Physiol. 136, 3396-3408. doi: 10.1104/pp.104.046441

Buchner, P., Takahashi, H., and Hawkesford, M. J. (2004b). Plant sulphate transporters: co-ordination of uptake, intracellular and long-distance transport. J. Exp. Bot. 55, 1765-1773. doi: 10.1093/jxb/erh206

Burandt, P., Papenbrock, J., Schmidt, A., Bloem, E., Haneklaus, S., and Schnug, E. (2001). Genotypical differences in total sulfur contents and cysteine desulfhydrase activities in Brassica napus L. Phyton 41, 75-86.

Burlacu, M. C., Leonte, C., Lipsa, F., Simioniuc, D. P., and Lazarescu, E. (2012). Identifiction of some cultivras of Brassica napus with resistence at Verticillium longisporum. Res. J. Agric. Sci. 44, 14-18.

Buxdorf, K., Yaffe, H., Barda, O., and Levy, M. (2013). The effects of glucosinolates and their breakdown products on necrotrophic fungi. PLoS ONE 8:e70771. doi: 10.1371/journal.pone.0070771

Chaerle, L., Hagenbeek, D., Vanrobaeys, X., and Van Der Straeten, D. (2007). Early detection of nutrient and biotic stress in Phaseolus vulgaris. Int. J. Remote Sens. 28, 3479-3492. doi: 10.1080/01431160601024259

Computational Biology and Functional Genomics Laboratory. (2014). Available online at: http://compbio.dfci.harvard.edu/ [Accessed 15.06.2014].

Cooper, R. M., Resende, M. L. V., Flood, J., Rowan, M. G., Beale, M. H., and Potter, U. (1996). Detection and cellular localization of elemental sulphur in disease-resistant genotypes of Theobroma cacao. Nature 379, 159-162. doi: $10.1038 / 379159 \mathrm{a} 0$

Dämmgen, U., Walker, K., Grünhage, L., and Jäger, H.-J. (1998). “The atmospheric sulphur cycle," in Sulphur in Agroecosystems, eds E. Schnug, R. F. Hüttl, and H. Beringer (Dordrecht: Kluwer), 75-114.

Dewanto, V., Wu, X., Adom, K. K., and Liu, R. H. (2002). Thermal processing enhances the nutritional value of tomatoes by increasing total antioxidant activity. J. Agric. Food Chem. 50, 3010-3014. doi: 10.1021/jf0115589

D’Hooghe, P., Escamez, S., Trouverie, J., and Avice, J. C. (2013). Sulphur limitation provokes physiological and leaf proteome changes in oilseed rape that lead to perturbation of sulphur, carbon and oxidative metabolisms. BMC Plant Biol. 13:23. doi: 10.1186/1471-2229-13-23

Dudonné, S., Vitrac, X., Coutière, P., Woillez, M., and Mérillon, J. M. (2009). Comparative study of the antioxidant properties and total phenolic content of 30 plant extracts of industrial interest using DPPH, ABTS, FRAP, SOD, and ORAC assay. J. Agric. Food Chem. 57, 1768-1774. doi: 10.1021/jf803011r

Dunker, S., Keunecke, H., Steinbach, P., and von Tiedemann, A. (2008). Impact of Verticillium longisporum on yield and morphology of winter oilseed rape (Brassica napus) in relation to systemic spread in plant. J. Phytopathol. 156, 698-707. doi: 10.1111/j.1439-0434.2008.01429.x

Eberlein, C. V., Morra, M. J., Guttieri, M. J., Brown, P. D., and Brown, J. (1998). Glucosinolate production by five field-grown Brassica napus cultivars used as green manures. Weed Technol. 12, 712-718.

Enyck, C., Koopmann, B., and von Tiedemann, A. (2009). Identification of Brassica accessions with enhanced resistance to Verticillium longisporum under controlled and field conditions. J. Plant Dis. Protect. 116, 63-72.

Expert, D., Franza, T., and Dellagi, A. (2012). "Iron in plant-pathogen interactions," in Molecular Aspects of Iron Metabolism in Pathogenic and Symbiotic Plant-Microbe Assiciations, eds D. Expert and M. R. O’Brian (New York, NY: Springer Briefs in Molecular Science), 7-40.

Floerl, S., Druebert, C., Majcherczyk, A., Karlovsky, P., Kües, U., and Polle, A. (2008). Defence reactions in the apoplastic proteome of oilseed rape (Brassica napus var. napus) attenuate Verticillium longisporum growth but not disease symptoms. BMC Plant Biol. 8:129. doi: 10.1186/1471-2229-8-129

Friedt, W., and Snowdon, R. (2009). "Oilseed rape," in Handbook of Plant Breeding, Vol. 4: Oil Crops Breeding, eds J. Vollmann and R. Istvan (New York, NY: Springer), 91-126.

Grant, C., and Kovar, J. (2012). Don't overlook sulfur in crop management. Fluid J. $20,10-12$.

Grant, O. M., Chaves, M. M., and Jones, H. G. (2006). Optimizing thermal imaging as a technique for detecting stomatal closure induced by drought stress 
under greenhouse conditions. Physiol. Plant. 127, 507-518. doi: 10.1111/j.13993054.2006.00686.x

Grierson, C., Nielsen, E., Ketelaarc, T., and Schiefelbein, J. (2014). Root hairs. Arabidopsis Book 12:e172. doi: 10.1199/tab.0172

Guretzki, S., and Papenbrock, J. (2013). Comparative analysis of methods analyzing effects of drought on herbaceous plants. J. Appl. Bot. Food Chem. 86, 47-54. doi: 10.5073/JABFQ.2013.086.007

Halkier, B. A., and Gershenzon, J. (2006). Biology and biochemistry of glucosinolates. Annu. Rev. Plant Biol. 57, 303-333. doi: 10.1146/annurev.arplant.57.032905.105228

Haneklaus, S., Bloem, E., Schnug, E., de Kok, L., and Stulen, I. (2007). “Sulfur," in Handbook of Plant Nutrient, eds A. V. Barker and D. J. Pilbeam (New York, NY: CRC Press), 183-238.

Heale, J. B., and Karapapa, K. V. (1999). The Verticillium threat to Canada's major oilseed crop: Canola. Can. J. Plant Pathol. 21, 1-7. doi: 10.1080/07060661.1999.10600114

Holmes, M. R. J. (1980). Nutrition of the Oilseed Rape Crop. London: Applied Science Publishers.

Huseby, S., Koprivova, A., Lee, B.-R., Saha, S., Mithen, R., Wold, A.-B., et al. (2013). Diurnal and light regulation of sulphur assimilation and glucosinolate biosynthesis in Arabidopsis. J. Exp. Bot. 64, 1039-1048. doi: 10.1093/jxb/ers378

Iñiguez-Luy, F. L., and Federico, M. L. (2011). "The genetics of Brassica napus L.," in Genetics and Genomics of the Brassicaceae, eds I. Bancroft and R. Schmidt (New York, NY: Springer), 291-322.

James, R. A., and Sirault, X. R. R. (2012). Infrared thermography in plant phenotyping for salinity tolerance. Methods Mol. Biol. 913, 173-189. doi: 10.1007/9781-61779-986-0_11

Jones, H. G. (2007). Monitoring plant and soil water status: established and novel methods revisited and their relevance to studies of drought tolerance. J. Exp. Bot. 58, 119-130. doi: 10.1093/jxb/erl118

Kitajima, M., and Butler, W. L. (1975). Excitation spectra for photosystem I and photosystem II in chloroplasts and the spectral characteristics of the distributions of quanta between the two photosystems. Biochim. Biophys. Acta 408, 297-305. doi: 10.1016/0005-2728(75)90131-0

Klepacka, J., Gujska, E., and Michalak, J. (2011). Phenolic compounds as cultivarand variety-distinguishing factors in some plant products. Plant Foods Hum. Nutr. 66, 64-69. doi: 10.1007/s11130-010-0205-1

Kopriva, S., Muheim, R., Koprivova, A., Trachsel, N., Catalano, C., Suter, M., et al. (1999). Light regulation of assimilatory sulphate reduction in Arabidopsis thaliana. Plant J. 20, 37-44. doi: 10.1046/j.1365-313X.1999.00573.x

Kruse, C., Haas, F. H., Jost, R., Reiser, B., Reichelt, M., Wirtz, M., et al. (2012). Improved sulfur nutrition provides the basis for enhanced production of sulfur-containing defense compounds in Arabidopsis thaliana upon inoculation with Alternaria brassicicola. J. Plant Physiol. 169, 740-743. doi: 10.1016/j.jplph.2011.12.017

Kruse, C., Jost, R., Lipschis, M., Kopp, B., Hartmann, M., and Hell, R. (2007). Sulfur-enhanced defence: effects of sulfur metabolism, nitrogen supply, and pathogen lifestyle. Plant Biol. 9, 608-619. doi: 10.1055/s-2007-965432

Lewandowska, M., and Sirko, A. (2008). Recent advances in understanding plant response to sulfur-deficiency stress. Acta. Biochim. Pol. 55, 457-471.

Lo, S. C., and Nicholson, R. L. (1998). Reduction of light-induced anthocyanin accumulation in inoculated sorghum mesocotyls. Implications for a compensatory role in the defense response. Plant Physiol. 116, 979-989. doi 10.1104/pp.116.3.979

Muneer, S., Lee, B. R., Kim, K. Y., Park, S. H., Zhang, Q., and Kim, T. H. (2014). Involvement of sulphur nutrition in modulating iron deficiency responses in photosynthetic organelles of oilseed rape (Brassica napus L.). Photosynth. Res. 119, 319-329. doi: 10.1007/s11120-013-9953-8

Ogura, H. (1968). Studies of the new male sterility in Japanese radish with special reference to the utilization of this sterility towards the practical raising of hybrid seeds. Mem. Fac. Agric. Kagoshima Univ. 6, 39-78.

Parmar, S., Buchner, P., and Hawkesford, M. J. (2007). Leaf developmental stage affects sulfate depletion and specific sulfate transporter expression during sulfur limitation in Brassica napus L. Plant Biol. 9, 647-653. doi: 10.1055/s-2007965428

Prabhu, A. S., Frageria, N. K., and Berni, R. F. (2007). "Phosphorus and plant disease," in Mineral Nutrition and Plant Disease, eds L. E. Datnoff, W. H. Elmer, and D. M. Huber (Minnesota: APS press), 45-56.
Quackenbush, J., Liang, F., Holt, I., Pertea, G., and Upton, J. (2000). The TIGR Gene Indices: reconstruction and representation of expressed gene sequences. Nucl. Acids Res. 28, 141-145. doi: 10.1093/nar/28.1.141

Rabino, I., and Mancinelli, A. L. (1986). Light, temperature, and anthocyanin production. Plant Physiol. 81, 922-924. doi: 10.1104/pp.81.3.922

Rausch, T., and Wachter, A. (2005). Sulfur metabolism: a versatile platform for launching defence operations. Trends Plant Sci. 10, 503-509. doi: 10.1016/j.tplants.2005.08.006

R Core Team. (2014). R: A Language and Environment for Statistical Computing. Vienna: R Foundation for Statistical Computing. Available online at: http:// www.R-project.org

Riemenschneider, A., Nikiforova, V., Hoefgen, R., De Kok, L. J., and Papenbrock, J. (2005). Impact of elevated $\mathrm{H}_{2} \mathrm{~S}$ on metabolite levels, activity of enzymes and expression of genes involved in cysteine metabolism. Plant Physiol. Biochem. 43, 473-483. doi: 10.1016/j.plaphy.2005.04.001

Scherer, H. W. (2001). Sulphur in crop production-invited paper. Eur. J. Agron. 14, 81-111. doi: 10.1016/S1161-0301(00)00082-4

Schnug, E., Booth, E., Haneklaus, S., and Walker, K. C. (1995). "Sulphur supply and stress resistance in oilseed rape," in Proceedings of the 9th International Rapeseed Congress, Cambridge 1995, 229-231.

Schröder, C. (2013). Hohe Erträge wurzeln tief. Deutsche Saatveredelung AG, Schinkel. Innovation 4, 20-22.

Smith, B. J., and Kirkegaard, J. A. (2002). In vitro inhibition of soil microorganisms by 2-phenylethyl isothiocyanate. Plant Pathol. 51, 585-593. doi: 10.1046/j.13653059.2002.00744.x

Sokolowsky, V., Kaldenhoff, R., Ricci, M., and Russo, V. E. A. (1990). Fast and reliable mini-prep RNA extraction from Neurospora crassa. Fungal Genet. Newslett. $36,41-43$

Sperdouli, I., and Moustakas, M. (2012). Spatio-temporal heterogeneity in Arabidopsis thaliana leaves under drought stress. Plant Biol. 14, 118-128. doi: 10.1111/j.1438-8677.2011.00473.x

Van Wees, S. C. M., Chang, H. S., Zhu, T., and Glazebrook, J. (2003). Characterization of the early response of Arabidopsis to Alternaria brassicicola infection using expression profiling. Plant Physiol. 132, 606-617. doi: 10.1104/pp.103.022186

Vollmann, J., and Rajcan, I. (2009). "Oil crop breeding and genetics," in Oil Crops. Series: Handbook of Plant Breeding, Vol. 4, eds J. Vollmann and I. Rajcan (New York, NY: Springer ), 1-30.

Wang, W., Barnaby, J. Y., Tada, Y., Li, H., Tör, M., Caldelari, D., et al. (2011). Timing of plant immune responses by a central circadian regulator. Nature 470, 110-114. doi: 10.1038/nature09766

Williams, J. S., Hall, S. A., Hawkesford, M. J., Beale, M. H., and Cooper, R. M. (2002). Elemental sulfur and thiol accumulation in tomato and defense against a fungal vascular pathogen. Plant Physiol. 128, 150-159. doi: 10.1104/pp.010687

Witzel, K., Hanschen, F. S., Schreiner, M., Krumbein, A., Ruppel, S., and Grosch, R. (2013). Verticillium suppression is associated with the glucosinolate composition of Arabidopsis thaliana leaves. PLoS ONE 8:e71877. doi: 10.1371/journal.pone.0071877

Conflict of Interest Statement: The authors declare that the research was conducted in the absence of any commercial or financial relationships that could be construed as a potential conflict of interest.

Received: 30 September 2014; accepted: 06 January 2015; published online: 02 February 2015.

Citation: Weese A, Pallmann P, Papenbrock J and Riemenschneider A (2015) Brassica napus L. cultivars show a broad variability in their morphology, physiology and metabolite levels in response to sulfur limitations and to pathogen attack. Front. Plant Sci. 6:9. doi: 10.3389/fpls.2015.00009

This article was submitted to Plant Physiology, a section of the journal Frontiers in Plant Science.

Copyright (C) 2015 Weese, Pallmann, Papenbrock and Riemenschneider. This is an open-access article distributed under the terms of the Creative Commons Attribution License (CC BY). The use, distribution or reproduction in other forums is permitted, provided the original author(s) or licensor are credited and that the original publication in this journal is cited, in accordance with accepted academic practice. No use, distribution or reproduction is permitted which does not comply with these terms. 